\title{
Santo Tomé de Tórdea (Castroverde, Lugo). Análisis arqueológico de una iǵlesia de origen altomedieval
}

\author{
Santo Tomé de Tórdea (Castroverde, Lugo). \\ Archaeological analysis of a Church from the early middle ages \\ http://dx.doi.org'/10.15304/galll.37.5185
}

\author{
José Carlos Sánchez-Pardo \\ Investigador Ramón y Cajal, Área de Arqueoloxía, Departamento de Historia \\ Universidade de Santiago de Compostela \\ josecarlos.sanchez@usc.es
}

\section{Rebeca Blanco-Rotea}

Investigadora posdoutoral I2C Xunta de Galicia, Área de Arqueoloxía, Departamento de Historia Universidade de Santiago de Compostela

rebeca.blanco.rotea@usc.es

\section{Resumen}

La fábrica y las diversas piezas reutilizadas en la iğlesia parroquial de Santo Tomé de Tórdea y sus alrededores reflejan una largóa y rica evolución constructiva. Sin embarơo, pese a su gran interés histórico-arqueológico, este edificio apenas había sido estudiado hasta la fecha. En este artículo presentamos los resultados de un trabajo arqueológico de prospección y análisis estratigráfico mediante lectura veloz de esta iglesia. Nuestro estudio revela que la iglesia conserva restos in situ de una primera fase altomedieval que puede encuadrarse hacia inicios del siglo X. A esta fase le siguieron distintas reformas: una anterior al siglo XVI, otra en el siglo XVI, otra a inicios del siglo XVIII y por último una serie de reformas ya en época contemporánea.

Palabras Clave: Arqueología de la arquitectura, iglesias altomedievales, estratigrafía, técnicas constructivas.

\begin{abstract}
The bond and the various reused elements in the walls and surroundings of Santo Tomé de Tórdea parish church reflect a long and rich constructive evolution. However, despite its historical and archaeological importance, this building has barely been studied to date. In this article we present the results of an archaeological work of survey and quick stratigraphic analysis ("lettura veloce") of this church. Our study reveals that the church still preserves standing remains of an early medieval phase from the beginning of the tenth century AD. This phase was followed by different reforms: one before the sixteenth century, another in the sixteenth century, another one at the beginning of the eighteenth century and finally a series of reforms in contemporary times.
\end{abstract}

Keywords: Archaeology of architecture, early medieval churches, stratigraphy, constructive techniques. 


\section{INTRODUCCIÓN ${ }^{1}$}

La iglesia parroquial de Santo Tomé de Tórdea se sitúa en la ladera de un suave valle que forma el río Tórdea, en el municipio de Castroverde, a unos $18 \mathrm{~km}$ en línea recta al este de la ciudad de Lugo, a cuya provincia pertenece (figura 1). Concretamente la iglesia se emplaza en el extremo norte de la pequeña aldea de Tórdea, rodeada de un pequeño atrio y del cementerio parroquial (figura 2). En la actualidad se trata de un edificio de 9 metros de ancho por 13 de largo compuesto de una única nave rematada en una cabecera rectangular, con una sacristía adosada en su esquina noreste y cubierta a dos aguas (figuras 3, 4 y 5).

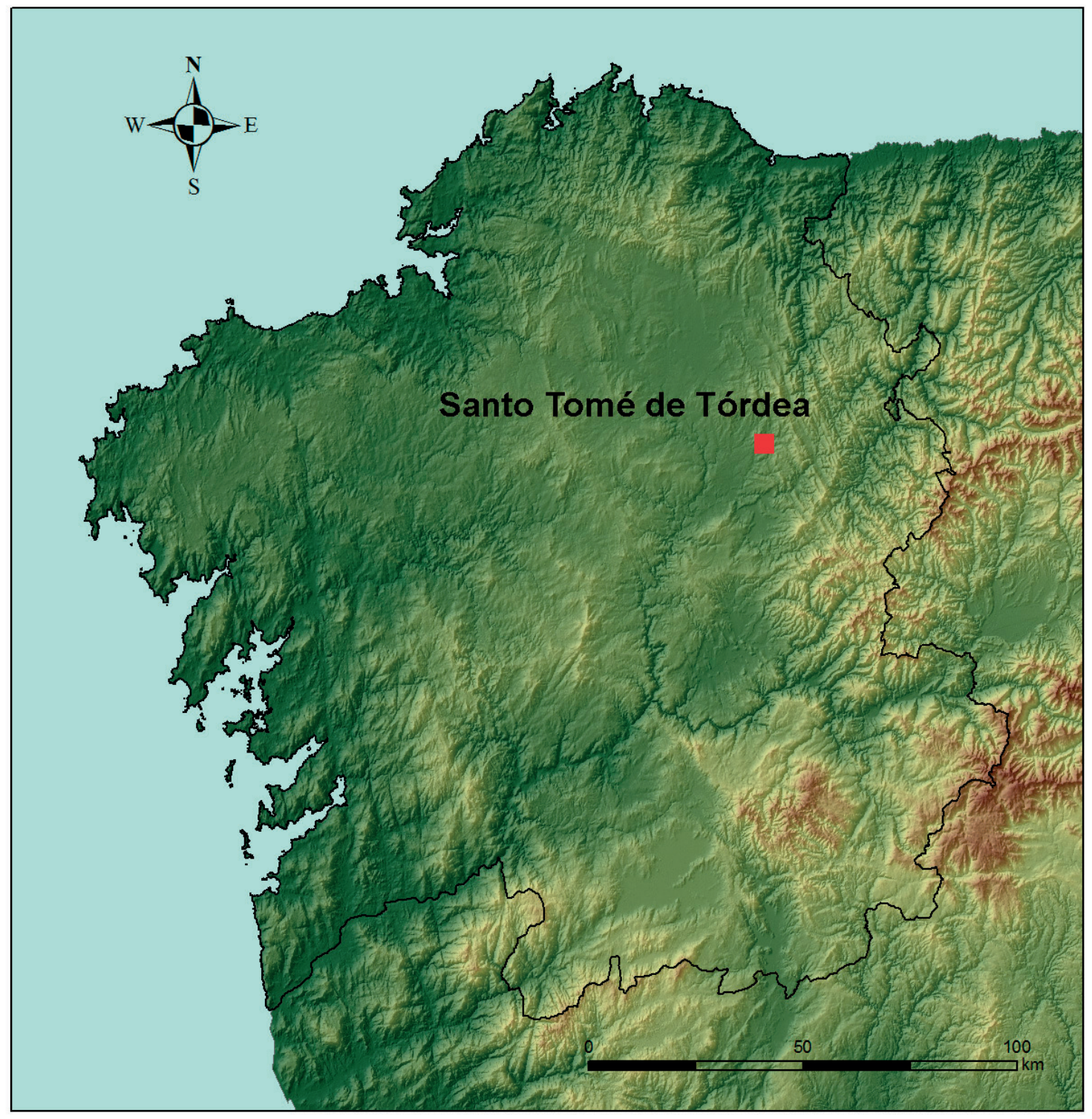

Figura 1. Mapa de localización de la iǵlesia de San Tomé de Tórdea en el Noroeste de la Península Ibérica.

1 Este artículo es resultado de los proyectos "EMCHAHE: Early Medieval Churches: History,Archaeology and Heritage" financiado por una ayuda Marie Curie CIG de la Unión Europea (PCIG12-GA-2012-334068) y "TERPOMED: Territorio y poder monástico en la Alta Edad Media”, financiado por un proyecto de excelencia de la Consellería de Cultura, Educación e Ordenación Universitaria de la Xunta de Galicia (PG-065, convocatoria Consolidación e Estructuración 2016). 


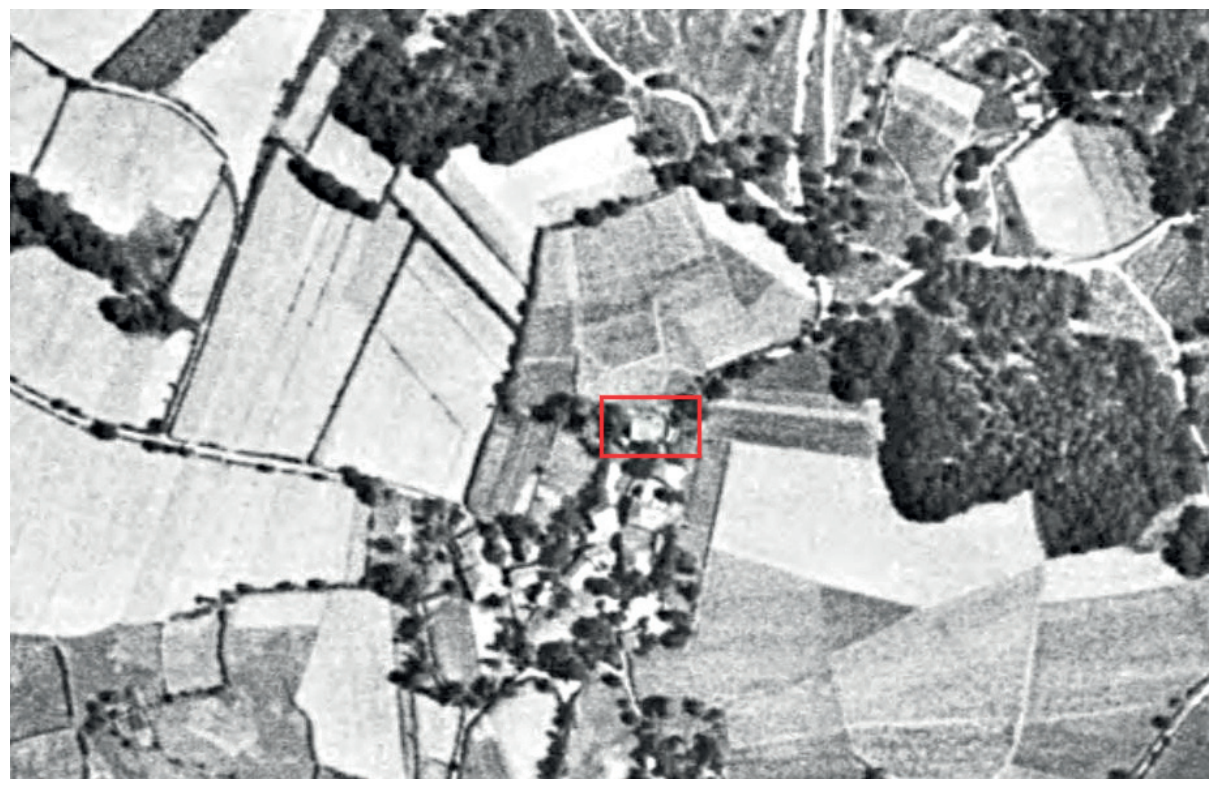

Figura 2. Fotografía aérea de la aldea de Tórdea en 1956 (“Vuelo americano serie B”). El rectángulo rojo indica la posición de la iglesia. Al norte de la iglesia se observan las marcas de un parcelario ligado a la misma. Imagen tomada del visor cartográfico de la Xunta https://mapas.xunta.es/visores/basico/ el día 6-6-2018.

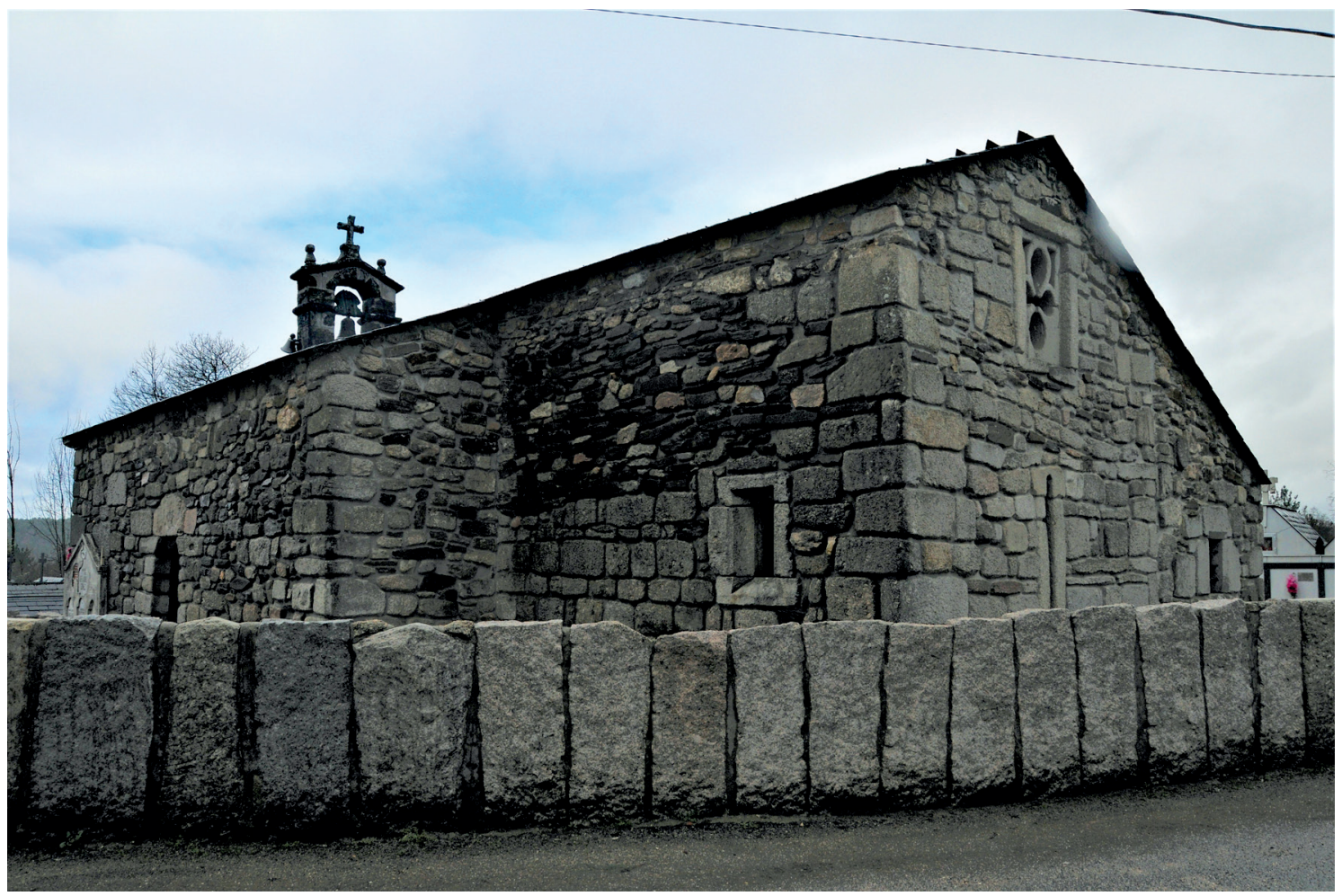

Figura 3. Imagen exterior de la iglesia de Santo Tomé de Tórdea desde el sureste. Fotografía de los autores. 


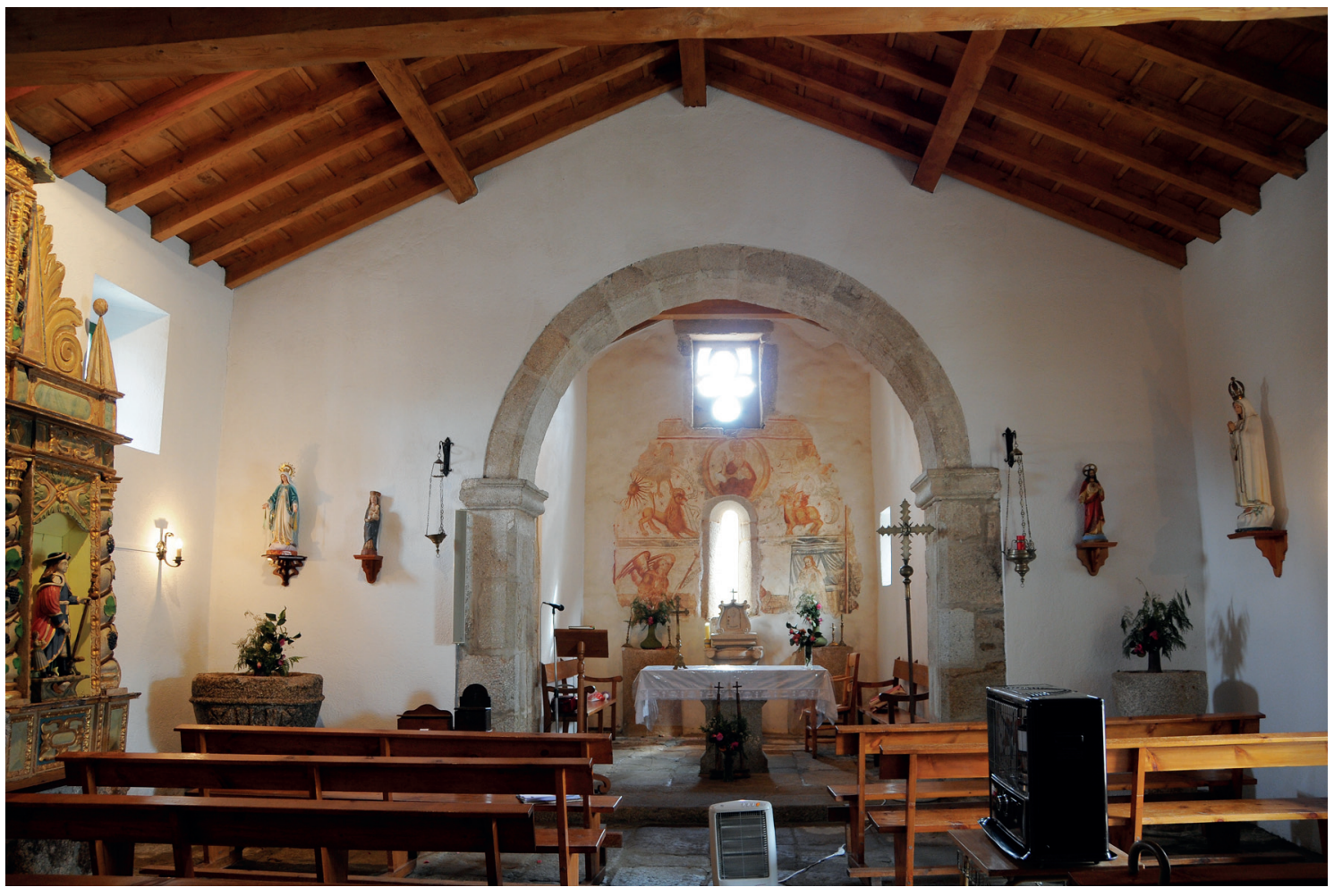

Figura 4. Imagen del interior de la iglesia. Fotografía de los autores.

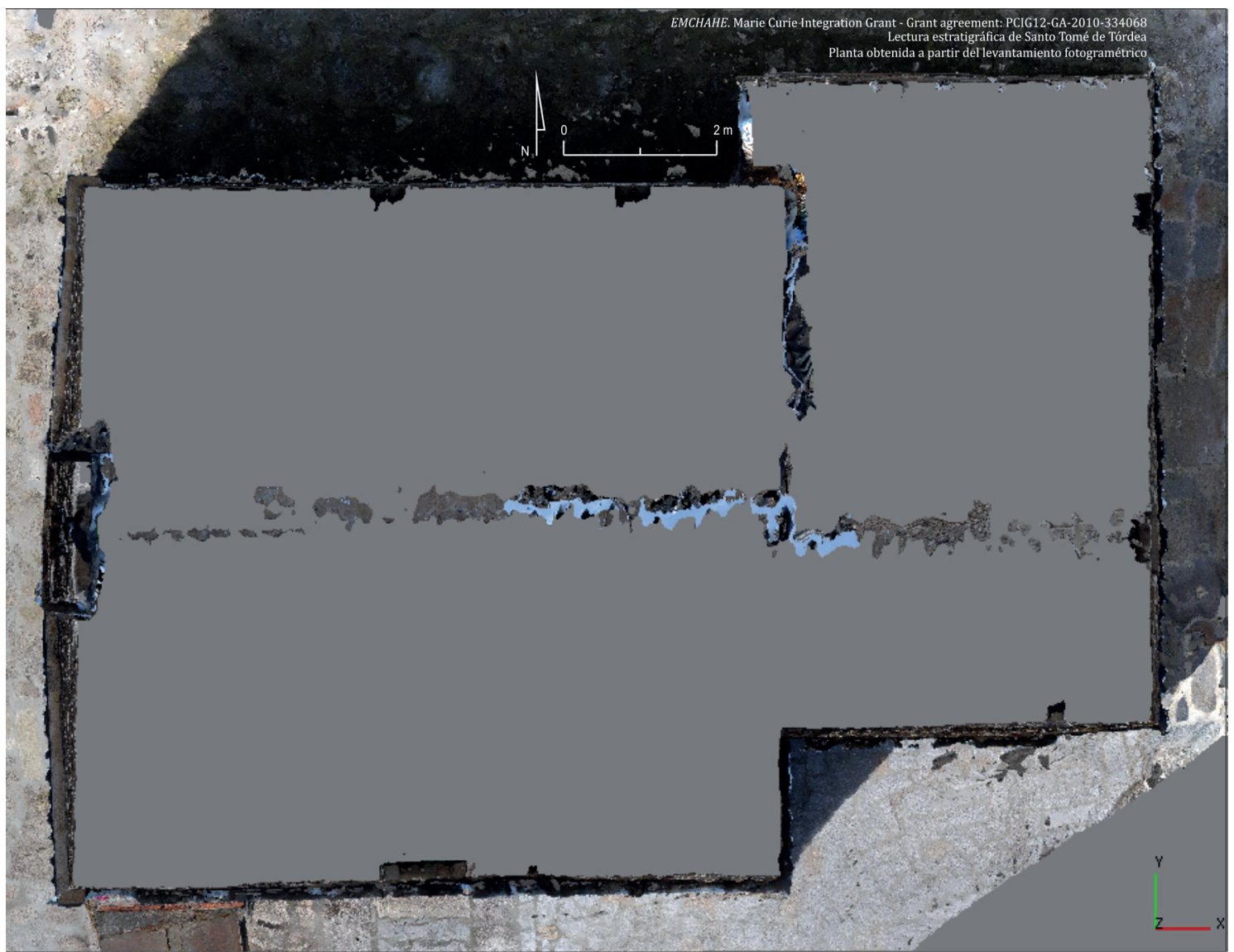

Figura 5. Planta de la iglesia de Tórdea elaborada a partir del modelo fotogramétrico de la misma. 
Pese a la presencia y aparición de diversos restos (arquitectónicos y funerarios) de época altomedieval en la iglesia y su entorno inmediato, el templo de Santo Tomé de Tórdea ha recibido poca atención por parte de los investigadores hasta la fecha. El primer estudio del edificio del que tenemos constancia se debe a Elías Valiña Sampedro quien considera que la fábrica primitiva podría haber sido románica y la restauración actual debió tener lugar en los siglos XV-XVI (VALIÑAS SAMPEDRO 1983: 127-128). Pero será Jaime Delgado quien realice el análisis más profundo de este templo llevado a cabo hasta la fecha, dentro de su amplia obra El románico de Lugo y su provincia. Según este autor, basándose en criterios principalmente estilísticos, la iglesia de Tórdea presenta una mezcla de estilos: visigótico-mozárabe, románico, renacentista y de época moderna, aunque su aspecto actual se debería en gran medida a las reformas de inicios del siglo XVIII, como indica una inscripción en el intradós de una de las dovelas del arco triunfal (DELGADO 1996-2006, vol. II: 52-60). De época prerrománica tan solo quedaría una ventana de cuatro óculos y dos ménsulas de la puerta sur decoradas con motivos geométricos. También nos informa este autor de la aparición en la década de 1970, de una lápida funeraria en una finca cercana a la iglesia, con fecha del año 794 (DELGADO 1996-2006, vol. II: 53-54) (figura 6). De la fase románica procedería, según el autor, la ventana saetera del ábside y la ventanita aspillera del muro sur, así como quizá alguna de las piezas de la espadaña, el dintel de la puerta sur y la pila bautismal. Por último, a una gran reforma realizada en el siglo XVI pertenecerían, estilísticamente, la puerta principal rematada en un arco de medio punto, los restos de una bóveda nervada y de algunas "gruesas columnas" y un gran capitel con parte de columna ubicado actualmente en el altar. Las pinturas interiores las sitúa en torno al año 1600. Este autor también nos informa de que el edificio fue recientemente restaurado por el párroco Abel Quiroga, quien, entre otras obras, habría procedido a quitar el encalado que lo recubría por el exterior (DELGADO 1996-2006, vol. II: 52-60). Posteriores trabajos tan sólo mencionan la adscripción altomedieval de algunas de las piezas procedentes de la iglesia. Para A. Rodríguez Colmenero “dos modillones y otros motivos” de esta iglesia serían ejemplos de arte "visigótico" que recupera motivos prerromanos (RODRÍGUEZ COLMENERO 2005:

Figura 6. Anverso y reverso de la lápida funeraria con la fecha del año 794 encontrada en las inmediaciones de la iglesia de Tórdea. Fotografía tomada del panel explicativo del interior del templo.

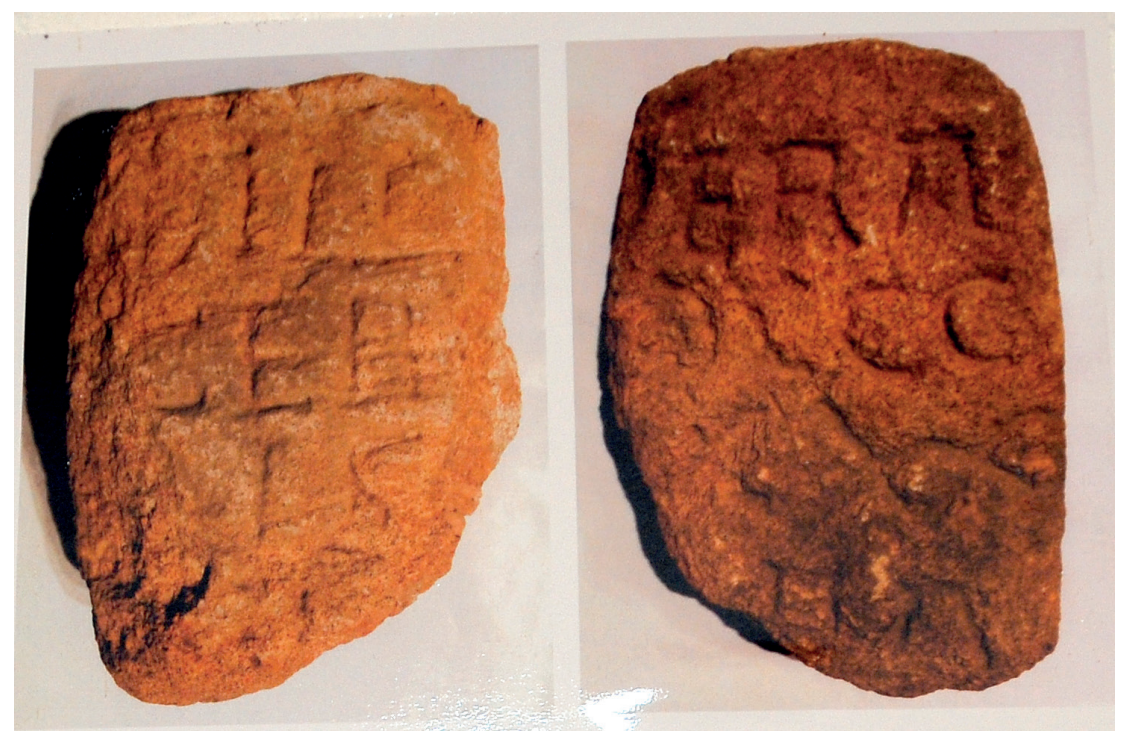


46), mientras que para I. Cabarcos la ménsula inferior de la puerta sur sería una ménsula de rollo vertical similar a otras de Ourense y fechable en siglo IX o inicios del X (CABARCOS 2006-2008: 239).

La documentación medieval resulta ambigua a la hora de rastrear los orígenes de esta iglesia. En el testamento del obispo Pelayo de Lugo en 998 a favor de la catedral lucense se mencionan las heredades que poseía en "Sancto Iuliano de Tordena" (CAÑIZARES 2012: doc. 69). La misma iglesia vuelve a aparecer citada en un inventario de posesiones de la iglesia lucense de la primera mitad del siglo XII, como "Sancti Iuliani de Tordenela" (CAÑIZARES 2012: doc. 248). Si priorizamos el mantenimiento de la advocación, podría tratarse de la actual iglesia de San Xulián de Pereiramá, ayuntamiento de Castroverde, en el curso alto del río Tórdea, no lejos de su lugar de nacimiento. Pero si nos centramos en el topónimo de la denominación, estas dos menciones pueden referirse a nuestra iglesia de San Tomé de Tórdea que podría haber cambiado de advocación en algún momento posterior a la mitad del siglo XII, aspecto sobre el cual, de momento, no tenemos constancia. Sin embargo, hay que tener en cuenta, efectivamente, que San Tomé es una dedicatoria bastante infrecuente en la documentación gallega del siglo X, mientras que San Julián sí es muy habitual. Ambas hipótesis son posibles, aunque la opción de que los documentos se refieran a Santo Tomé de Tórdea cuenta con el respaldo de la existencia de dichos restos prerrománicos. De ser cierta esta identificación, tendríamos documentada esta iglesia ya a finales del siglo X, pero es necesario avanzar con prudencia sobre este aspecto ${ }^{2}$.

Pese al interés de todos estos indicios, la iglesia de Santo Tomé de Tórdea no había sido objeto de ningún estudio arqueológico que tratase de aclarar su evolución constructiva. Es por ello que se decidió incluirla dentro del proyecto EMCHAHE centrado en el estudio de iglesias altomedievales gallegas (SÁNCHEZ-PARDO, BLANCO-ROTEA 2014). En este artículo presentaremos los resultados tanto de la prospección como del análisis estratigráfico de este edificio, para posteriormente plantear algunas valoraciones acerca de su evolución constructiva.

\section{Prospección ARQUeológica de la iglesia y SU ENTORNo}

En el marco de las prospecciones para la identificación y estudio de iglesias altomedievales dentro del proyecto EMCHAHE visitamos la iglesia de Santo Tomé de Tórdea en dos ocasiones en abril de 2014. En estas visitas resultó de gran valor la ayuda e información ofrecidas por el párroco de la iglesia, D. Abel Quiroga.

En una primera aproximación visual a su fábrica nos pareció identificar en el muro del ábside fases constructivas en alzado que podrían encajar, hipotéticamente y en base a paralelos conocidos, en una etapa prerrománica. Por otro lado, el párroco nos informó de que en las restauraciones de la iglesia realizadas en la década de 1980 se procedió a reconstruir prácticamente todo el muro norte, como se aprecia en las fotografías que de dicha restauración se exponen en el interior de la iglesia (figura 7).

2 Esta información ha sido recopilada en el marco del proyecto EMCHAHE por Marcos Fernández Ferreiro, a quien agradecemos profundamente su valiosa colaboración. 
Figura 7. Trabajos de reconstrucción del muro norte de la iglesia por los vecinos de la aldea de Tórdea en los años 80 del siglo XX. Fotografía tomada del panel explicativo del interior del templo.
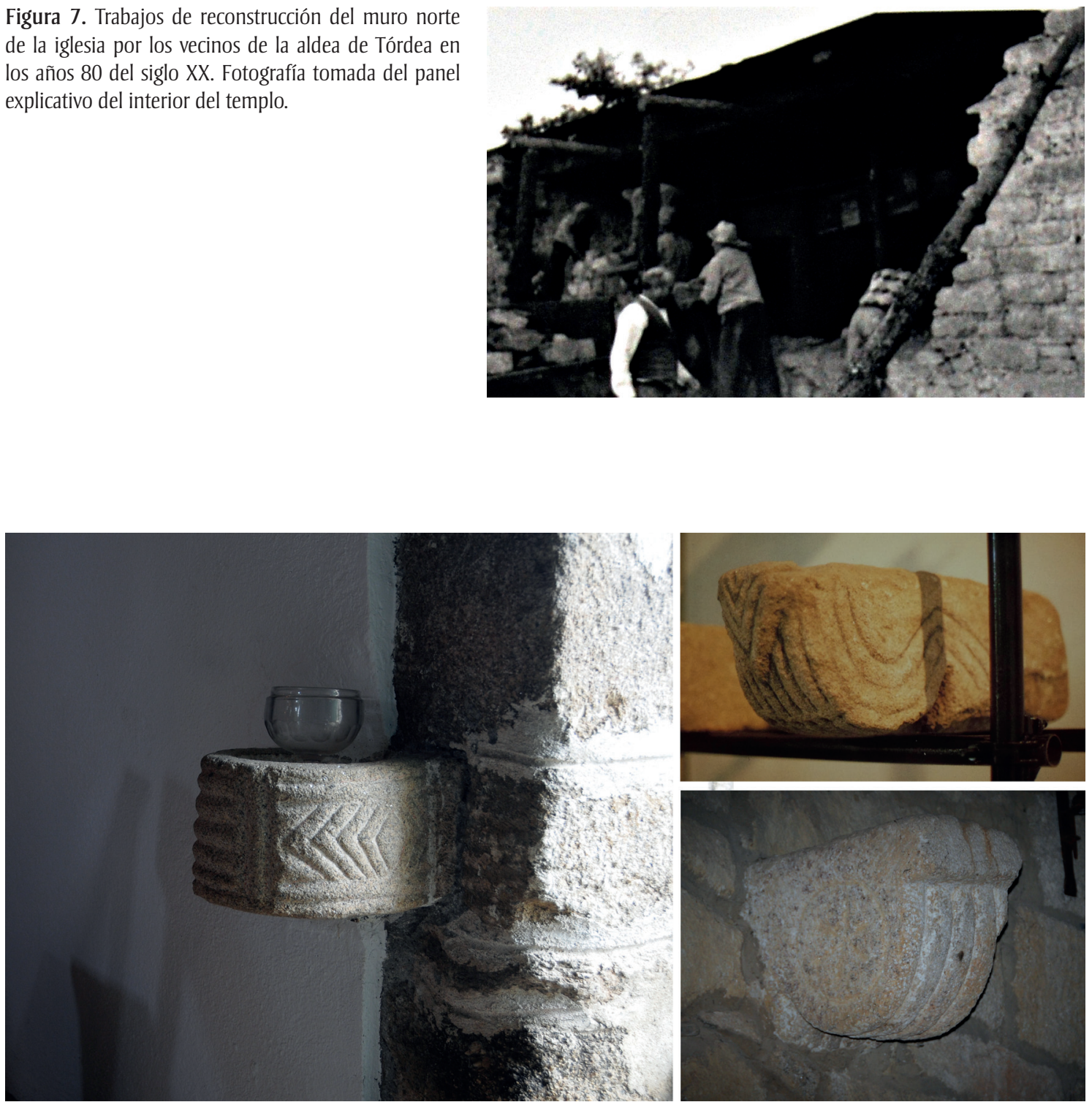

Figura 8. A la izquierda, ménsula prerrománica reutilizada como pila de agua bendita en el interior de la iglesia de Tórdea (fotografía de los autores). A la derecha, dos paralelos para dicho tipo de ménsulas: arriba, ménsula procedente de la antigua iglesia de "Sancta Ouxea ad Portum Abbatis" custodiada en el Museo provincial de Ourense (fotografía tomada de Yzquierdo 1993, p. 149), y abajo, ménsula reutilizada en Santa María de Mixós (Verín, Ourense) (fotografía de los autores).

En el interior de la iglesia, sirviendo de pila de agua bendita al lado de la puerta sur, se observa una pieza que a nuestro juicio debía ser una antigua ménsula con acanaladuras -similar a alguna conservada en Santa María de Mixós, en Verín- (figura 8) que fue posteriormente careada y decorada para completar la forma circular de pila de agua bendita. También pudimos comprobar que la pieza reutilizada en el exterior de la iglesia, que sirve de ménsula en la puerta sur, corresponde en realidad a una estela discoidea, bien conocidas por paralelos (EGUILETA et al. 1988; ARIAS VILAS 1998). Igualmente, reutilizado en el muro de una construcción muy cercana, al sur de la iglesia, observamos un modillón de 3 rollos realizado en granito. Se trata de una pieza inédita aunque probablemente se corresponda con una de las supuestas piezas de friso visigóticas mencionadas por Jaime Delgado (DELGADO 1996-2006, vol. II: 56) (figura 9). 


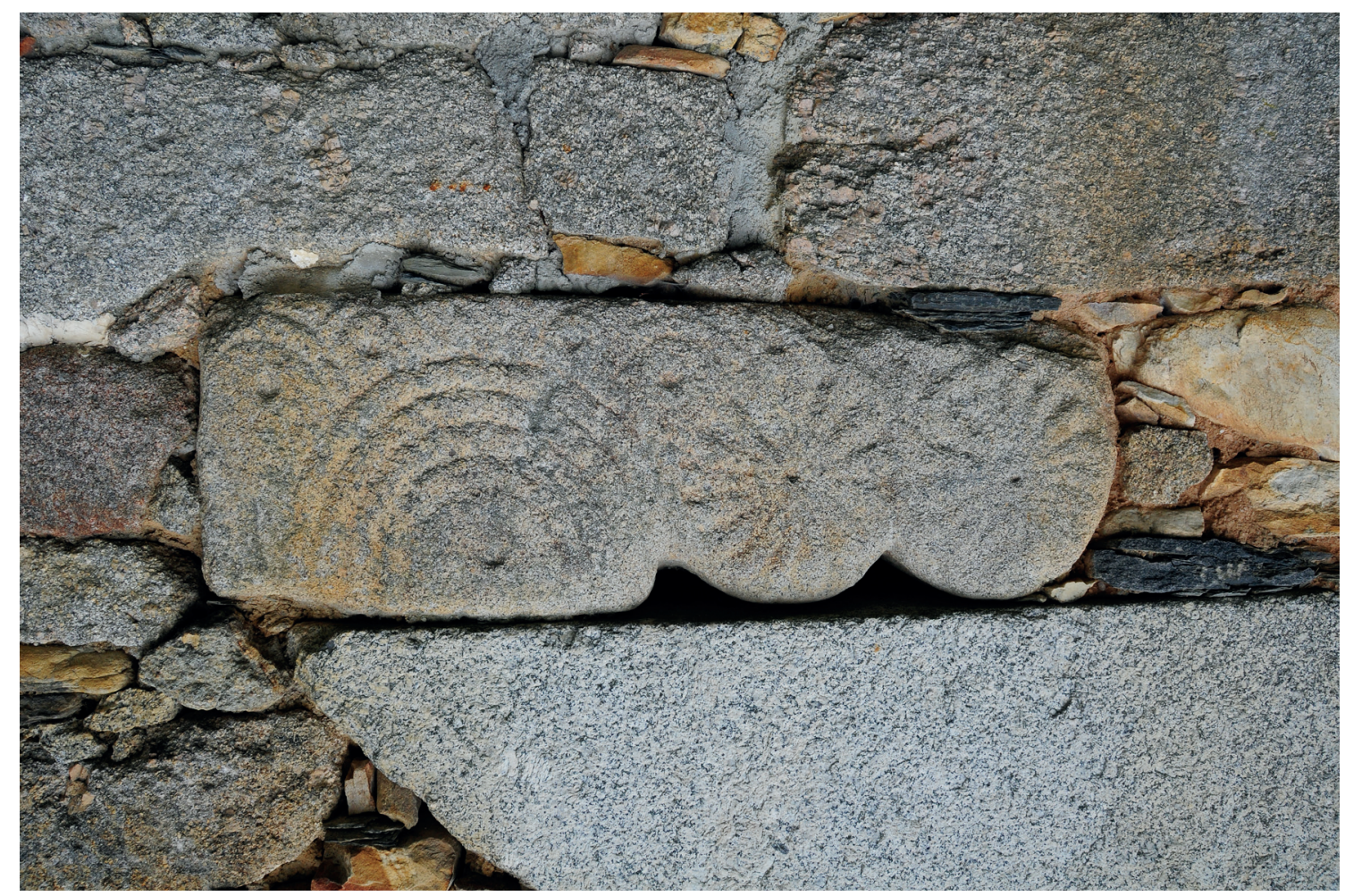

Figura 9. Modillón de rollos prerrománico empotrado en el muro exterior de una casa al sur de la iğlesia. Fotografía de los autores.

Centrándonos ya en el entorno de la iglesia, ésta se sitúa en la parte más elevada de un conjunto de terrazas agrícolas que en su mayoría parecen actualmente estar abandonadas. El párroco nos informó de que esta zona tenía abundantes cultivos cuando llegó en 1983 ya que es muy rica en agua. Efectivamente la fotografía aérea de 1956 ("Vuelo americano, serie B”) muestra un entorno intensamente cultivado y revela además las trazas de un interesante parcelario ligado a la iglesia, en su zona norte, que podría corresponder con su antiguo terrazgo o "dextro" (figura 2). D. Abel Quiroga también nos comentó que en esta zona abundan los cantos rodados de formación natural, y que por ello han sido utilizados tradicionalmente como elemento de construcción en este lugar, como se observa en los muros de la propia iglesia y en otras construcciones del entorno.

El párroco Abel Quiroga nos informó del lugar exacto de aparición de la lápida funeraria del año 794, en un prado situado a 180 metros al sur de la iglesia, en una zona más baja y cercana al río, en la que brota una fuente natural. A ese lugar los vecinos lo llaman "A Torre" y hay referencias a la aparición de cerámica en él, así como a leyendas de que ahí existía un antiguo poblado. En nuestra inspección visual no constatamos ningún indicio de carácter arqueológico de interés.

No lejos de esta aldea debía discurrir el trazado de la vía XIX romana según el itinerario de Antonino (RODRÍGUEZ COLMENERO et al. 2004: 255). Según nos indica el párroco, D. Abel Quiroga, a unos 100 metros de la iglesia, en un camino próximo aún se veía hace unos años un antiguo empedrado que correspondería a dicha vía, pero fue recientemente asfaltado. Sea parte de la vía romana o no el trazado descrito por el párroco, en la iglesia y su entorno inmediato se encuentran restos de varios miliarios. En el interior del ábside, apoyados contra la pared, hay dos mitades longitudinales de un miliario 
anepígrafe realizado en granito. En el esquinal suroeste de la iglesia se aprecia un bloque de granito alargado de sección semicircular reutilizado como sillar, y que semeja también la mitad de un miliario. Por las indicaciones de Jaime Delgado sabemos además, de la existencia de otro miliario en el atrio de la iglesia que actualmente se localizaría en casa de un vecino, y de parte de otro más que se encontraba en una esquina del atrio. En nuestra visita pudimos comprobar que dicho miliario ha sido transportado a un terreno cercano a la iglesia. Se trata un miliario partido horizontalmente cerca de su base para aprovechar la piedra (figura 10).
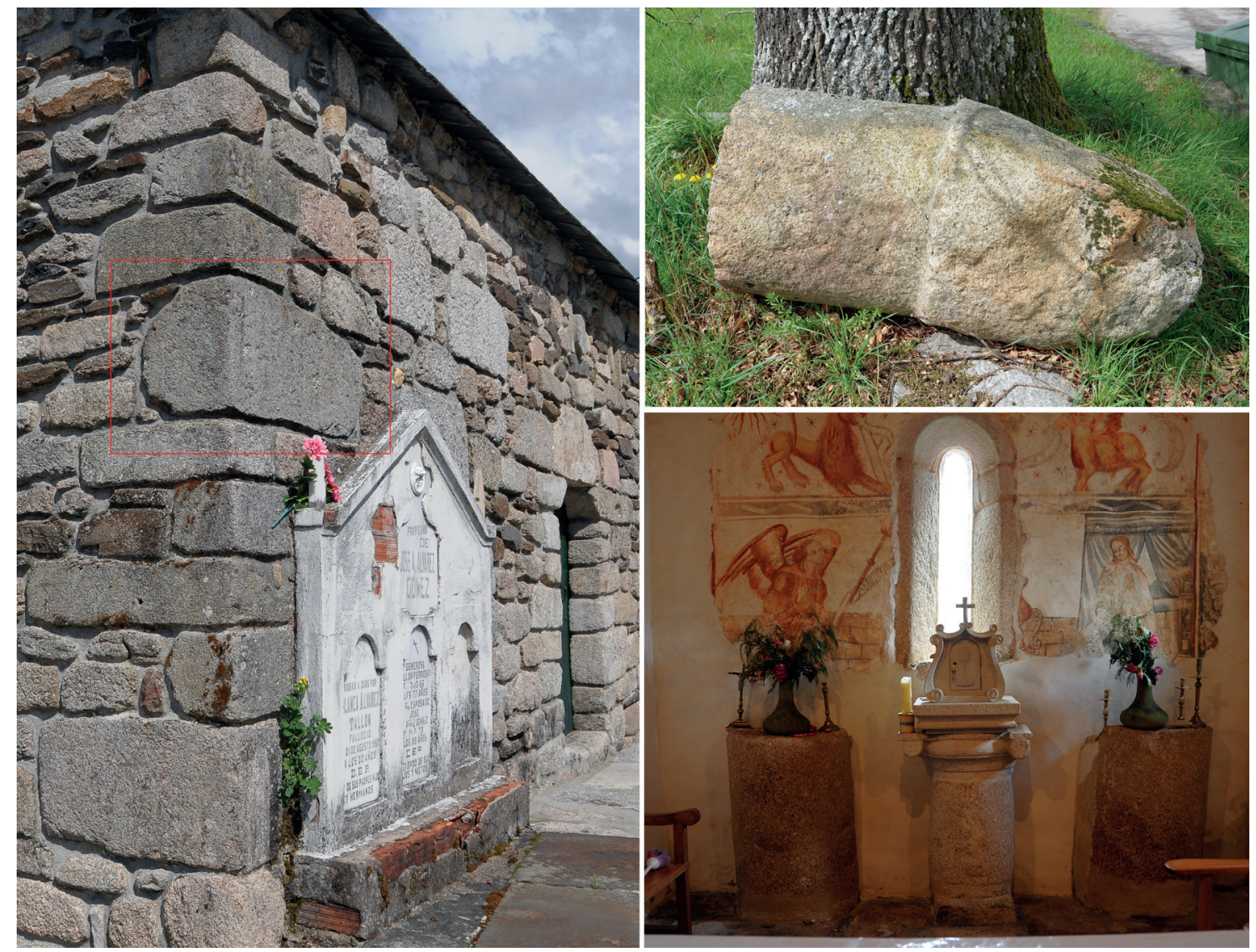

Figura 10. Fraǵmentos de antiguos miliarios romanos reutilizados en la iglesia de Tórdea y su entorno. A la izquierda (indicado por el rectángúlo rojo), mitad de un miliario reaprovechado como sillar en el esquinal Suroeste de la iǵlesia. Arriba a la derecha, fragmento inferior de miliario en un campo a 80 metros al sur de la iglesia. Abajo a la izquierda, dos mitades longitudinales de miliario apoyadas contra el ábside en el interior de la iglesia. Fotografías de los autores.

\section{LECTURA ESTRATIGRÁFICA}

Con el objetivo de comprobar la hipótesis planteada durante la prospección de la existencia de fases altomedievales in situ, procedimos a realizar un análisis estratigráfico completo de la iglesia de Tórdea. Concretamente se llevó a cabo una lectura veloz de paramentos o de registro rápido, una aproximación bien establecida para otras zonas (BROGIOLO 1988: 33; CABALLERO 1995, 1996; SÁNCHEZ ZUFIAURRE 2007), y que ya ha sido aplicada por nuestro equipo a otros casos gallegos (SÁNCHEZ-PARDO et al. 
2017). La diferencia entre una lectura veloz y una convencional radica en el uso de listados de Unidades Estratigráficas (en adelante UEs), donde se simplifica el volumen de información recogida sobre cada UE, en vez de fichas analíticas de registro, agilizando la fase de toma de datos en campo. En todo caso el método de trabajo, al igual que en la lectura estratigráfica convencional, se basa en la diferenciación de las UEs in situ, su posterior plasmación sobre un soporte gráfico (Figuras 12, 13, 14 y 15), el registro de las UE en fichas simplificadas (tabla 1), la elaboración del diagrama estratigráfico (Figura 16) y los posteriores procesos de correlación, síntesis y datación. En el caso de Santo Tomé de Tórdea tan solo se realizó la lectura del exterior de la iglesia, ya que el interior se encuentra completamente revestido.

Dado que no contábamos con una planimetría publicada del edificio, se decidió desarrollar un modelo fotogramétrico empleando el software Agisoft PhotoScan Pro. Para ello, se llevaron a cabo una serie de fotografías de todo el conjunto y se escaló el modelo con las medidas tomadas en campo. El resultado es un modelo 3D métrico representativo de la forma y aspecto de los elementos seleccionados con aspecto realista y otra versión sin textura (figura 11) que permite advertir otros aspectos, como las inscripciones o grabados (MAÑANA-BORRAZÁS et al. 2016).

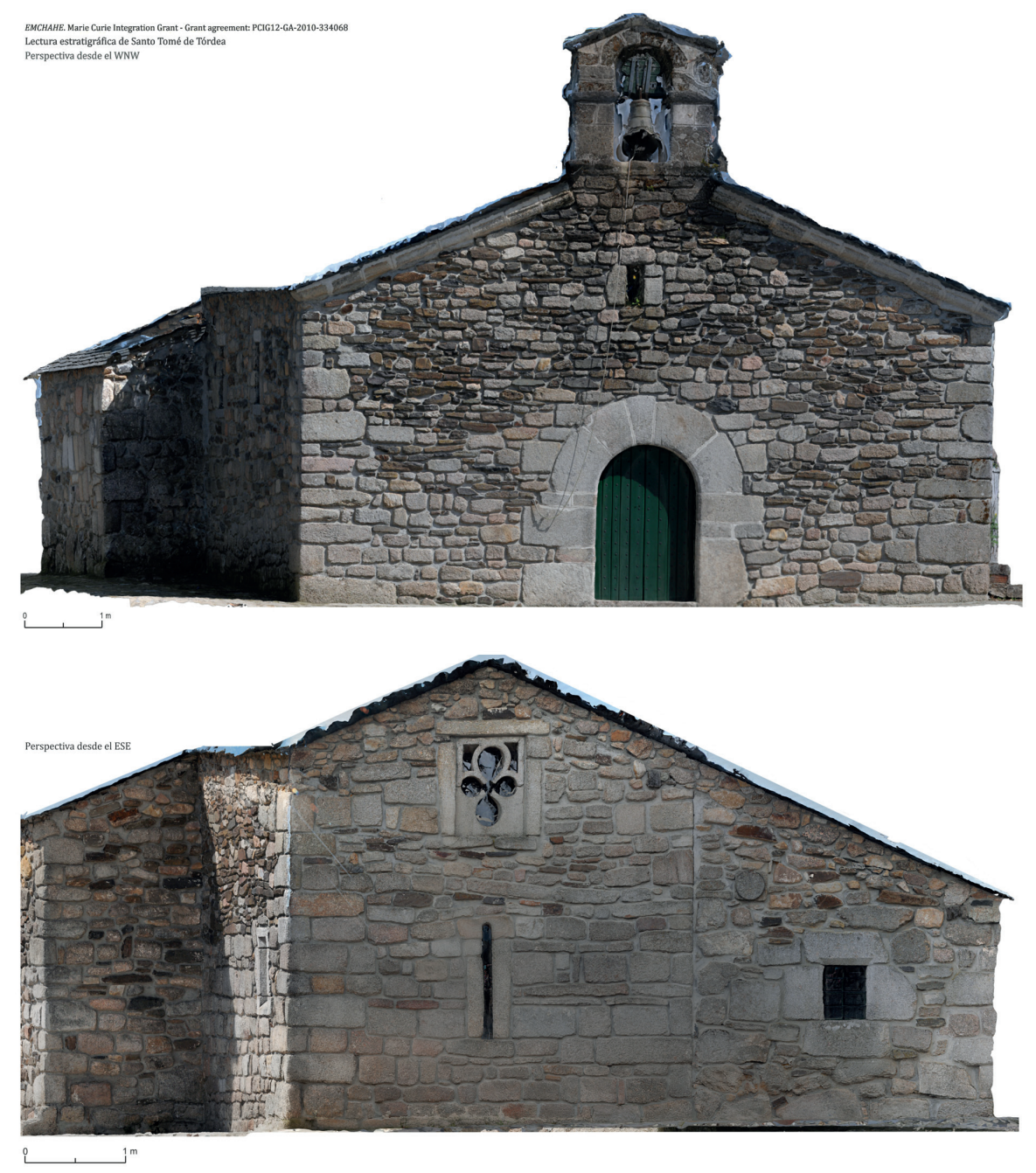

Figura 11. Imagen fotogramétrica de los alzados oeste y este de la iglesia de Tórdea. 
Por último, hay que advertir que la lectura estratigráfica se vio altamente afectada por el grueso rejuntado al que fueron sometidos los muros de la iglesia, así como al empleo del mismo tipo de piedra (procedentes en su mayor parte del cercano río Tórdea) a lo largo de sus distintas fases de reforma.

La lectura estratigráfica ha revelado la existencia de cinco fases constructivas que pasamos a describir a continuación:

\section{Fase I: altomedieval (siglo X)}

A esta fase pertenece, en primer lugar, la parte inferior del alzado sur y el este del ábside. La UE001 corresponde al muro que conforma la parte baja del alzado este (hasta el dintel de la ventana-saetera) y el esquinal SE del ábside. Está formado por una sillería de granito dispuesta a soga y tizón en las esquinas y un sillarejo irregular en el muro, alternado con una hilada de sillería a la altura de la base de la ventana saetera. Los materiales empleados son fundamentalmente granito de grano grueso, aunque documentamos un ladrillo macizo, empleado en el desdoble de una hilada, que podría ser reutilizado (es el único que se ha documentado en toda la iglesia). La forma de los materiales es bastante irregular (en forma y tamaño), aunque tiende a ser rectangular y están dispuestos a soga. También se documentan piezas cuadrangulares, otras que son de tipo laja (muy alargadas) y alguna más irregular, con las esquinas rotas, lo que podría indicar que podrían estar reutilizadas. Las piezas se disponen siguiendo hiladas, pero en muchas ocasiones estas se rompen y las hiladas doblan. La zona más irregular, y en la que se emplean piezas de menor tamaño, se localiza debajo de la ventana-saetera. Las juntas son muy anchas y actualmente están rellenas de un mortero de cemento portland reciente (UE025), y se encuentran rehundidas. En el muro, hacia la parte baja, se localiza una larga ventana saetera, formada por una laja en el alfeizar, una pieza monolítica en la jamba norte, dos piezas en la sur (la inferior rectangular y la superior cuadrangular) y una pieza de remate formando un arquillo de medio punto. Esta pieza es de grano más fino que las otras y conserva huellas de gradina, que creemos habría que relacionar con un posible repicado de los muros exteriores de la iglesia para dotarla de un revestimiento. El esquinal SE conserva mayor altura que el NE, prácticamente cubre toda la altura de los alzados del ábside.

También forma parte de esta fase el muro de sillarejo regular localizado en la mitad inferior del muro sur del ábside (UEoo2). Está realizado con piezas rectangulares y cuadrangulares, generalmente dispuestas a soga (aunque se aprecian algunos tizones). Los sillarejos se disponen siguiendo hiladas horizontales, bastante regulares, en alguna zona las hiladas doblan, pero se hace puntualmente, posiblemente al disponer material de mayor tamaño reutilizado. Se aprecia una alternancia en la altura de las hiladas, las dos inferiores son iguales, les sigue otra de menor altura, dos iguales que las inferiores, otra de menor altura, una más alta, otra de menor altura, otra más alta, otra de menor altura, y una más alta. La parte superior del muro está cortada. Por su extremo este se adosa al muro UEo01. En la parte superior este está cortado por la UEo03 para disponer una ventana adintelada con doble derrame en la Fase III, que se incluye dentro de la UEoo4. Inicialmente habíamos separado esta UE de la UEoo1, ya que parecía presentar un apa- 
rejo más regular en la disposición de las piezas, así como la propia regularidad de las mismas dentro de cada hilada. Sin embargo, éste es un recurso en el que se combinan dos tipos de aparejos, el sillarejo con la sillería, que ya hemos visto utilizado en otros edificios analizados en el proyecto EMCHAHE, como San Martiño de Pazó (SÁNCHEZ-PARDO ET al. 2017). Por otra parte, el muro de sillarejo continúa las hiladas del esquinal, lo que le confiere una homogeneidad constructiva y cronológica. En el caso de Pazó, el muro original se dató en el siglo X.

De igual modo, el zócalo documentado en el esquinal SE de la nave (UEoo8), sería parte de esta primera fase. Está realizado con piezas de tamaño medio de granito de grano grueso. El zócalo sobresale del paño del muro y tiene una orientación distinta a la de la nave, al menos el alzado sur. Conserva 1 hilada en el alzado sur y 2 en el este. La piedra que hace esquina es la que más sobresale de la planta de la nave y está cortada haciendo un escalón. Por la forma, podría tratarse de una moldura reutilizada. No obstante, resulta difícil observar bien el aparejo de esta UE, ya que se conserva muy poco en altura y está tapado parcialmente por el mortero de cemento UE025. Podría ser bastante similar a la UE002, con la que mantiene un contacto directo, pero no es posible observar bien la unión entre ambas por el mortero. Tal vez se trate de los restos de una planta anterior, con una orientación distinta a la actual, o sea el zócalo de la UEoo9, que está bastante alterada en altura. Por tanto, las UEs 001, 002 y 008 podrían corresponder a la misma UE, pero dada la presencia del mortero reciente que no permite observar las juntas entre ellas con claridad, preferimos mantenerlas separadas, aunque dentro de la misma fase.

También en el muro norte, estarían englobadas (con ciertas dudas) en esta fase las tres hiladas de sillarejo situadas en la parte inferior de dicho muro norte de la nave, en la mitad oeste (UE012). Se trata de piezas de granito de grano grueso dispuestas en hiladas horizontales, aunque algo inclinadas, por lo que las hiladas van desapareciendo bajo el nivel del suelo actual, a medida que avanzamos hacia la parte este del muro. Aunque tiene cierta similitud con la UE013, se han diferenciado dos UEs porque la inferior es más regular y presenta características similares a la UEoo8.

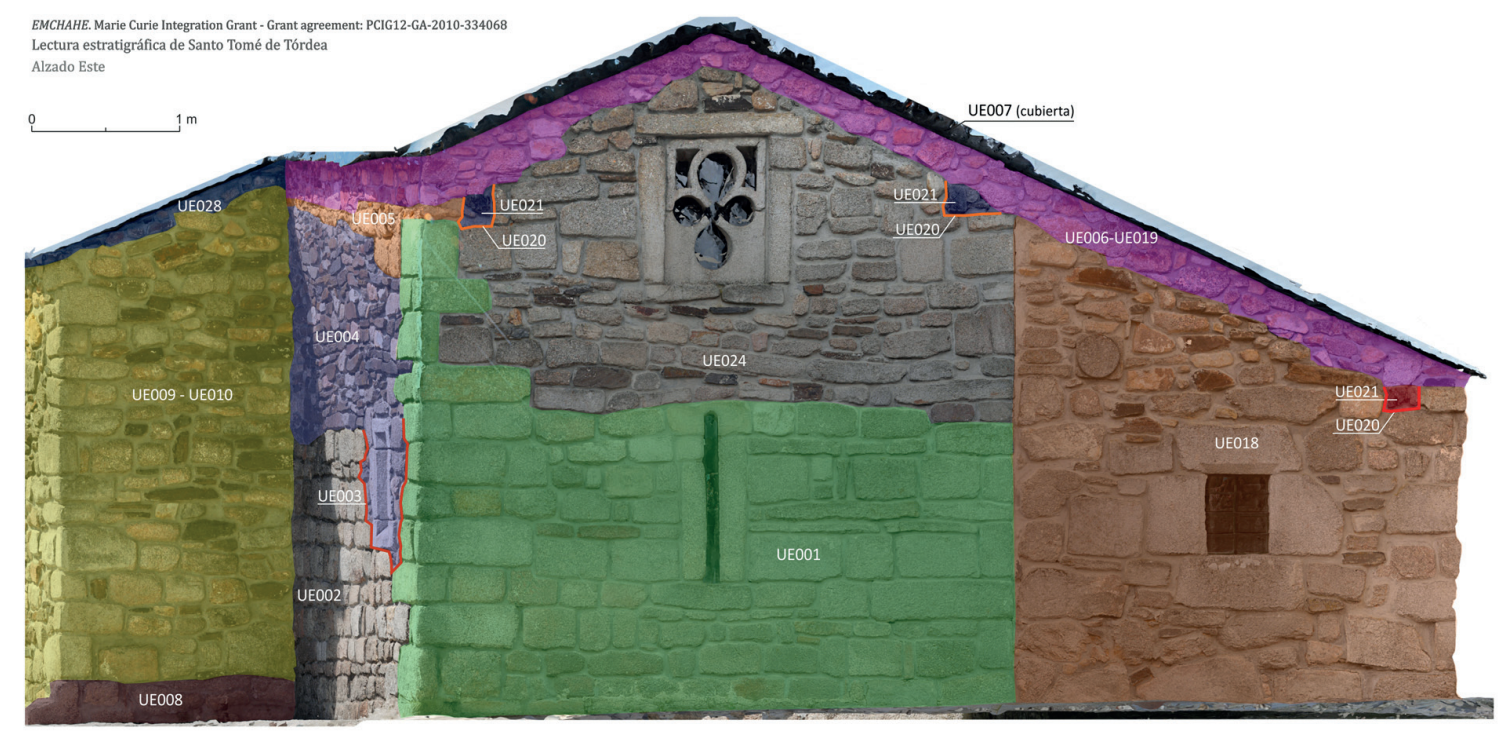

Figura 12. Diferenciación de unidades estratigráficas en el sector este de la iglesia. 


\section{Fase II: anterior o coetánea al siglo XVI}

A esta fase pertenece el muro localizado en la parte alta del alzado este del ábside (UE024). Está realizado en un aparejo de sillarejo irregular. La base presenta hiladas inclinadas, y en la parte alta pseudohiladas horizontales que doblan y ondulan. Incluye el esquinal NE de sillería encadenada. Se reutiliza una gran ventana-celosía cuadrilobulada en la parte superior. Como materiales se emplea granito de grano grueso y fino, esquisto muy pizarroso y un canto rodado; también se documenta sobre la ventana un ladrillo macizo. Hay algunas piezas de granito largas similares a las utilizadas en la UEoo1. Entre las UEoo1 y UE024 se detecta un cambio de aparejo, pero, como decimos, el mortero de cemento (UE025) que se ha aplicado a todas las juntas rehundidas en una reciente restauración desvirtúa en gran manera el aparejo del muro; aun así, creemos que la diferencia entre ambos es bastante clara, sobre todo en cuanto a la falta de similitud que se aprecia entre el esquinal NE y el SE. Hemos decidido separar esta reforma (UE024) de las reformas de la fase III (adscritas al siglo XVI) ya que las pinturas del interior de la iglesia, que se asocian estilísticamente al renacimiento, tapan parcialmente la celosía cuadrilobulada, por lo que deben ser posteriores a ésta. Por tanto, creemos que el muro que incluye la ventana-celosía debe ser anterior a las pinturas, es decir, a la fase III.

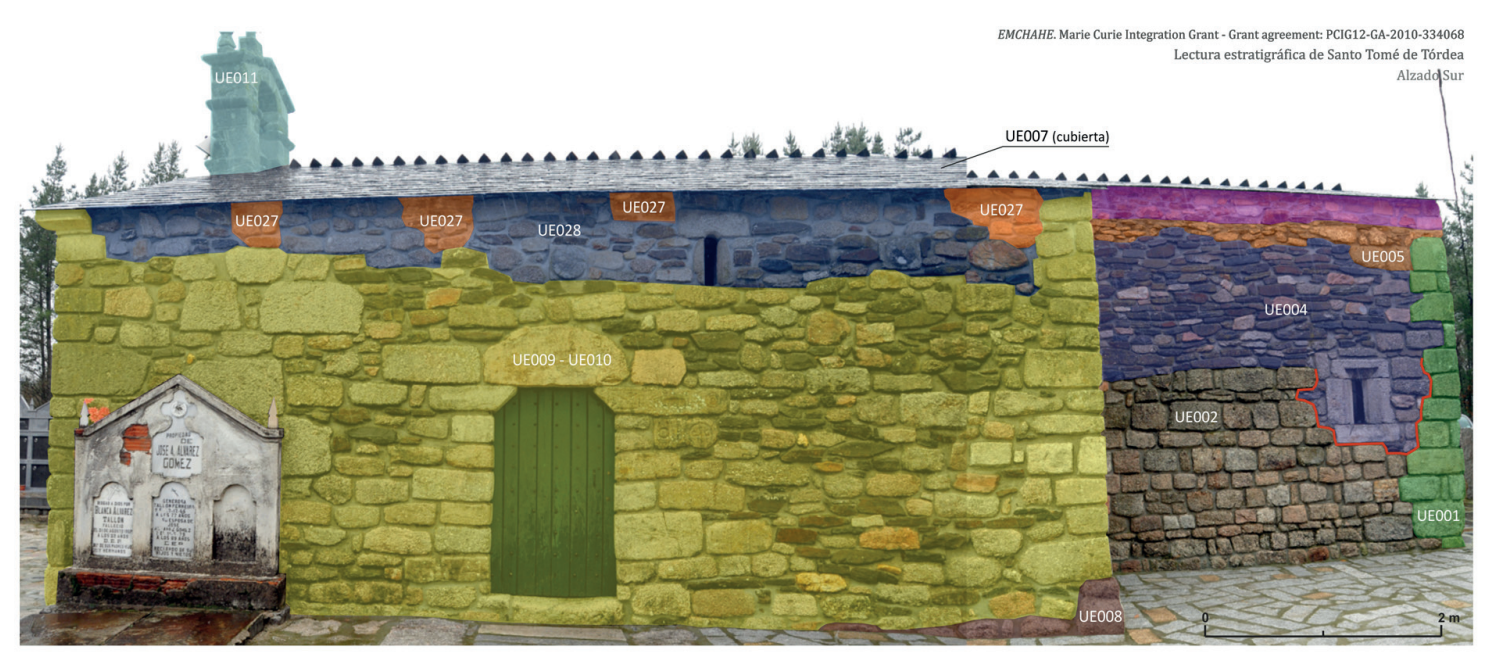

Figura 13. Diferenciación de unidades estratigráficas en el sector sur de la iglesia.

\section{Fase III: siglo XVI}

La fase III corresponde a la obra renacentista de la iglesia llevada a cabo en el siglo XVI. A ella pertenece buena parte de la fachada oeste de la iglesia, de la nave sur y parte de la nave norte (UEoo9, UE010 y UE011). Por el ritmo de la lectura, se dieron UEs distintas para cada uno de estos sectores, y porque se apreciaban ciertas diferencias en los paramentos, pero tras realizar los procesos de análisis, síntesis y correlación, hemos concluido que se trata de la misma UE, ya que responden al mismo proceso constructivo 
y emplean un aparejo mixto que utiliza sillería y mampostería con materiales heterogéneos y reutilizados, por lo que se unificaron como parte de la misma acción constructiva. Se trata, por tanto, del muro que conforma los paramentos sur y oeste de la nave y parte del norte (el esquinal oeste), que colapsó posteriormente. Está realizado en un aparejo de mampostería con piezas de tamaño pequeño-medio de esquisto, granito, cuarcita y canto rodado; muchas de estas piezas son materiales reutilizados. Las piezas se disponen horizontalmente formando pseudohiladas, también se aprecia alguna hilada de regularización. Presenta una mayor regularidad en la parte baja del muro, sobre todo en la parte norte del paramento oeste y la parte oeste del paramento sur. Los esquinales y los vanos están realizados en sillería de granito, formada por piezas irregulares y materiales reutilizados (miliarios romanos, estelas posiblemente altomedievales); en los esquinales los sillares se disponen encadenados. La fachada sur incluye un vano, a modo de saetera rematado en un pequeño arquillo, aunque corresponde a una fase posterior (UE028); una puerta de jambas rectas rematadas por ménsulas lisas (UE009-010, una de ellas es una pieza decorada y debajo presenta una estela, ambas posiblemente altomedievales) sobre las que descansa un tímpano sin decorar. La puerta al interior está rematada por un arco mixtilíneo, formado por piezas de granito con la cara que forma el arco en curva; las piezas se disponen escalonadas, de manera que se genera este tipo de arco. En la fachada oeste incluye una puerta realizada en sillería de gran tamaño, con sillares de granito de grano fino. Está rematada por un arco de medio punto adovelado. Sobre la puerta se localiza una ventana saetera rectangular y sobre esta una espadaña de un solo cuerpo, rematada por un arco de medio punto y una cruz sencilla con pináculos a los lados. La fachada está rematada por una moldura formada por un filete y cuarto bocel. En la fachada norte se conserva únicamente el esquinal de sillería encadenada reutilizada.

También formaría parte de esta fase la UE013. Se trata de un muro de sillarejo de granito de grano grueso situado en la parte inferior del muro norte de la nave, en prácticamente toda su extensión. Se emplea algún material reutilizado (como una posible dovela). Se dispone en hiladas que tienden a la horizontalidad, aunque se inclinan, alguna dobla o forma pseudohiladas. Esta UE parece coetánea al muro UE011, tal y como se documenta en el paramento sur, ya que tiene cierta similitud con él. Parece pues que se empleó sillería en el esquinal (UEo11) y sillarejo en la parte baja del muro, que como hemos visto para el caso de la UEo11 es más regular en dicha parte baja. Como ya vimos, en este muro la UE013 se apoya sobre un muro también de sillarejo (UEo12) que presenta las hiladas perfectamente horizontales. Aunque mantienen algunas similitudes entre sí, lo cierto es que el muro UE012 parece más regular, por ello, lo hemos vinculado a una UE diferente que, por su posición estratigráfica sería anterior. Pero, nuevamente, las juntas de cemente rehundido alteran la visión del aparejo, por lo que podría tratarse de dos UEs contemporáneas. Sólo otro tipo de estudios permitiría avanzar en este aspecto, pero, por el momento, preferimos atender al criterio tipológico para diferenciar ambos muros. 
En la cabecera pertenecerían a esta fase las UEoo3 y UE004. La UE004 corresponde al muro de mampostería irregular de pequeño/medio tamaño, realizado sobre todo con lajas de esquisto y algún mampuesto de granito, situado en el alzado sur del ábside, sobre el muro UE002. Las piezas se disponen horizontalmente y tienden a formar hiladas, aunque ondulantes e inclinadas y, en muchos casos, se cortan. Parece tratarse de una reparación en altura del alzado sur del ábside. Por la relación estratigráfica parece ser posterior al alzado sur-este de la nave. Incluye una ventana rectangular adintelada, con doble derrame realizada con cuatro piezas de sillería de granito de grano grueso, cuyos bordes exteriores son irregulares. El hueco entre la ventana y el corte (UEoo3) para su apertura en el muro (UEO02) se rellena con piezas de granito reutilizadas (sillarejos), lajas y bloques de esquisto y un canto rodado de cuarcita. Llama la atención que en este muro, con respecto a los restantes de la iglesia, hay una mayor presencia de esquistos. Son abundantes también en el muro UE010, pero allí están mezclados con granito, más o menos en cantidades proporcionadas. La UEoo3, como ya hemos dicho, es un corte practicado en las UE001 y 002 para abrir una ventana. El corte se localiza en el lado este del muro UEoo2, aproximadamente hacia la parte central en altura del muro sur de ábside, y tiene forma irregular.

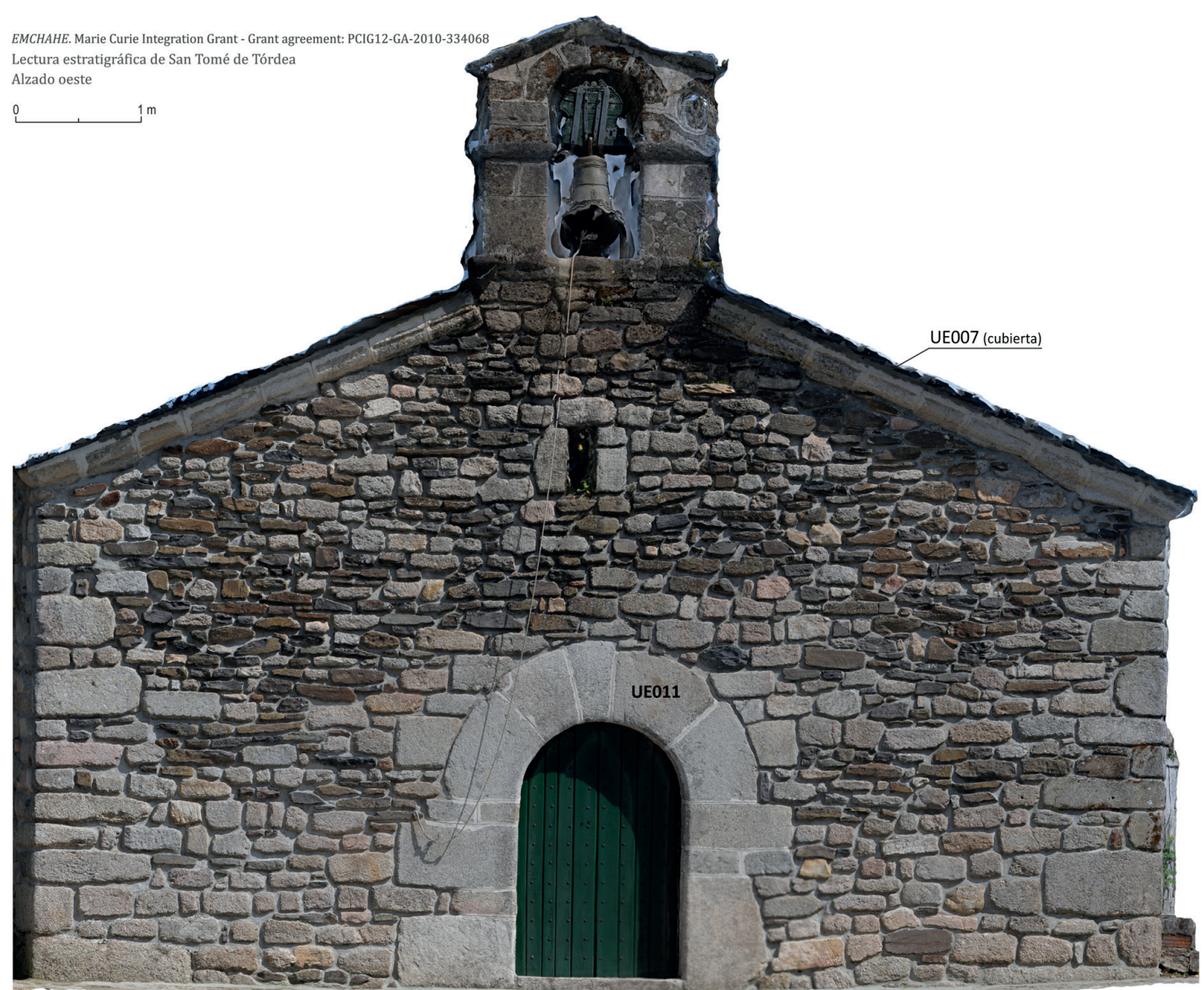

Figura 14. Diferenciación de unidades estratigráficas en el sector oeste de la iglesia. 


\section{Fase IV: reformas de inicios del siglo XVIII}

A esta fase se corresponden diversas reformas posteriores al siglo XVI, probablemente de inicios del siglo XVIII, como indica el epígrafe del interior del arco triunfal que contiene la fecha 1719.

En primer lugar, en esta fase se incluye la construcción de una sacristía adosada al paramento norte del ábside. La UE018 sería el muro perimetral, realizado en mampostería de gran tamaño con esquinales de sillería encadenada, que forma los paramentos norte, este y el esquinal oeste de la sacristía. Se documenta abundante material reutilizado, claves de bóveda (posiblemente del siglo XVI), sillares y piezas de ventanas. En la parte baja se dispone una hilada de grandes bloques sin trabajar. En algunas zonas el aparejo forma pseudohiladas. El alzado norte incluía una saetera hoy cegada con mortero de cemento (UE025). Todavía conserva las pizarras de la cubierta anterior (UE029) y las cabezas de las vigas, que han sido amortizadas dentro de la UE019 que eleva la altura de la sacristía. La UE017 corresponde a la posible reparación del alzado oeste de la sacristía (UE018). Está realizado en un aparejo de mampostería de granito, tanto de grano muy fino como muy grueso, algún esquisto o pizarra y algún canto rodado. Sobresale del paño del muro marcado por el esquinal NO de la UE018. No podemos asegurar con certeza si se trata de una reparación o si, por causa de la ruina de toda la fachada norte de la iglesia, se ha desplazado este lienzo hacia fuera, ya que la interfaz se produce en el encuentro entre el esquinal de sillería y el muro de mampostería. La UEo17 se apoya sobre un zócalo (UE026) que podría ser similar a los grandes bloques sin trabajar de la parte baja del muro norte de la sacristía, pero al estar cubierto de cemento (UE025) no se aprecia claramente la relación con el muro UE018. Son unas cinco piezas de granito que sobresalen irregularmente del muro.

A esta cuarta fase pertenecen también diversas UEs ligadas a la existencia de una cubierta anterior. En la cabecera, la UE005 es una reforma de mampostería irregular de granito de pequeño tamaño y algún sillar/bloque de granito reutilizado, situada sobre el muro UEoo4, a todo lo largo del mismo y posiblemente relacionada con una reforma para la construcción de esa cubierta hoy desaparecida. Con ella hay que vincular también los restos de una viguería que se localizan en el muro este del ábside (UEo20 y 021) y al oeste de la sacristía (UE022 y 023), así como una línea de pizarras (UE029) que se documenta de forma intermitente en el alzado norte de la sacristía y que corresponde al remate de esta cubierta anterior. Esa cubierta es, por tanto, posterior a la fecha de construcción de la sacristía que hemos adscrito al del siglo XVIII.

Como ya hemos dicho, la UE020 corresponde a tres mechinales rectangulares abiertos en las UE018 y UE024, para disponer unas vigas de madera de una cubierta anterior más baja que la actual. La UE021 corresponde a tres vigas de madera para sujetar la tablazón de la cubierta en la fachada este de la iglesia. Las vigas han sido amortizadas por la UE que levanta la estructura (UEoo6-019) y se relaciona con los restos de la cubierta anterior (UE029). La UE022 es otro mechinal rectangular abierto en las UE017 y UE018, para disponer una viga de madera que sujetaba dicha cubierta en el muro oeste de la sacristía. La UEo23 es la cabeza de viga de madera introducida en dicho mechinal. Las 
vigas han sido amortizadas por la UE que levanta la estructura (UEoo6-019). La UEo29 son los restos de lajas de pizarra de la anterior cubierta, que aún se aprecian en el muro norte de la sacristía.

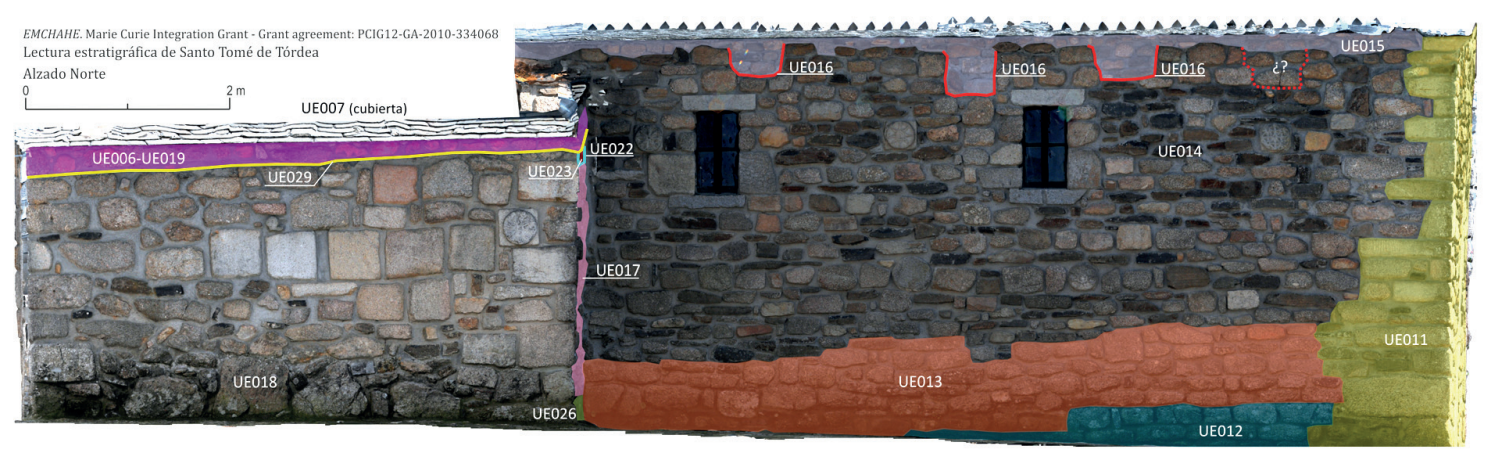

Figura 15. Diferenciación de unidades estratigráficas en el sector norte de la iǵlesia.

\section{Fase V: reformas contemporáneas del siglo $\mathrm{XX}$}

Esta fase corresponde a reformas contemporáneas, principalmente aquellas realizadas en 1985 por iniciativa del párroco don Abel Quiroga.

La UE014 es el muro que forma la mayor parte de la fachada norte de la nave y que corresponde a esa reforma. Se emplea una técnica mixta que combina la mampostería y el sillarejo. El muro tiene las juntas muy anchas, rehundidas y rellenas de mortero de cemento. Se emplea granito de grano grueso y fino, esquistos, pizarras y cantos rodados. Incluye numerosas piezas reutilizadas como claves de bóveda, una posible columna y un fragmento de epígrafe de época moderna, en el que se lee la palabra "misas"3. También incluye dos ventanas rectangulares adinteladas.

Otra serie de UEs están relacionadas con la construcción de la actual cubierta. La UE015 corresponde al remate del muro norte realizado en mampostería de pequeño tamaño con el objetivo de regularizar el remate del muro y disponer la cubierta. Lo mismo ocurre en el muro sur con la UE028, donde se regulariza su parte superior del alzado para disponer la cubierta, y por tanto es equiparable a las UEoo6-019 y 015. La UE016 son los cortes practicados en la UE014 relacionados con la construcción de la actual cubierta (UE015-UE007). Tienen forma cuadrangular y están rellenos por la UEo15. Posiblemente se trate del cierre de los mechinales para disponer las vigas de madera de la cubierta. Los mismos cortes se detectan en el coronamiento del muro sur (UE027). Por su parte, la UEo06-UE019 sería la elevación en la parte superior de los alzados sur y este del ábside, y este, norte y oeste de la sacristía para disponer la cubierta a la misma altura que la de la nave en el alzado sur de toda la iglesia. Se trata de un murete realizado con mampostería irregular de tamaño pequeño-medio, con piezas de granito, esquisto y canto rodado de cuarcita. Las juntas son anchas y están tomadas con mortero de cemen-

3 Agradecemos la valiosa ayuda prestada por la Dra. Helena Gimeno (Universidad de Alcalá de Henares) en el estudio de éste y otros epígrafes de la iǵlesia de Tórdea. 
to. Finalmente, la UEOO7 es la actual cubierta de pizarra a dos aguas, con la cumbrera entrelazada en crestería, que se dispone sobre la UEoo6-019.

Por último, tenemos el rejuntado de todas las fachadas exteriores de la iglesia con mortero de cemento (UE025).

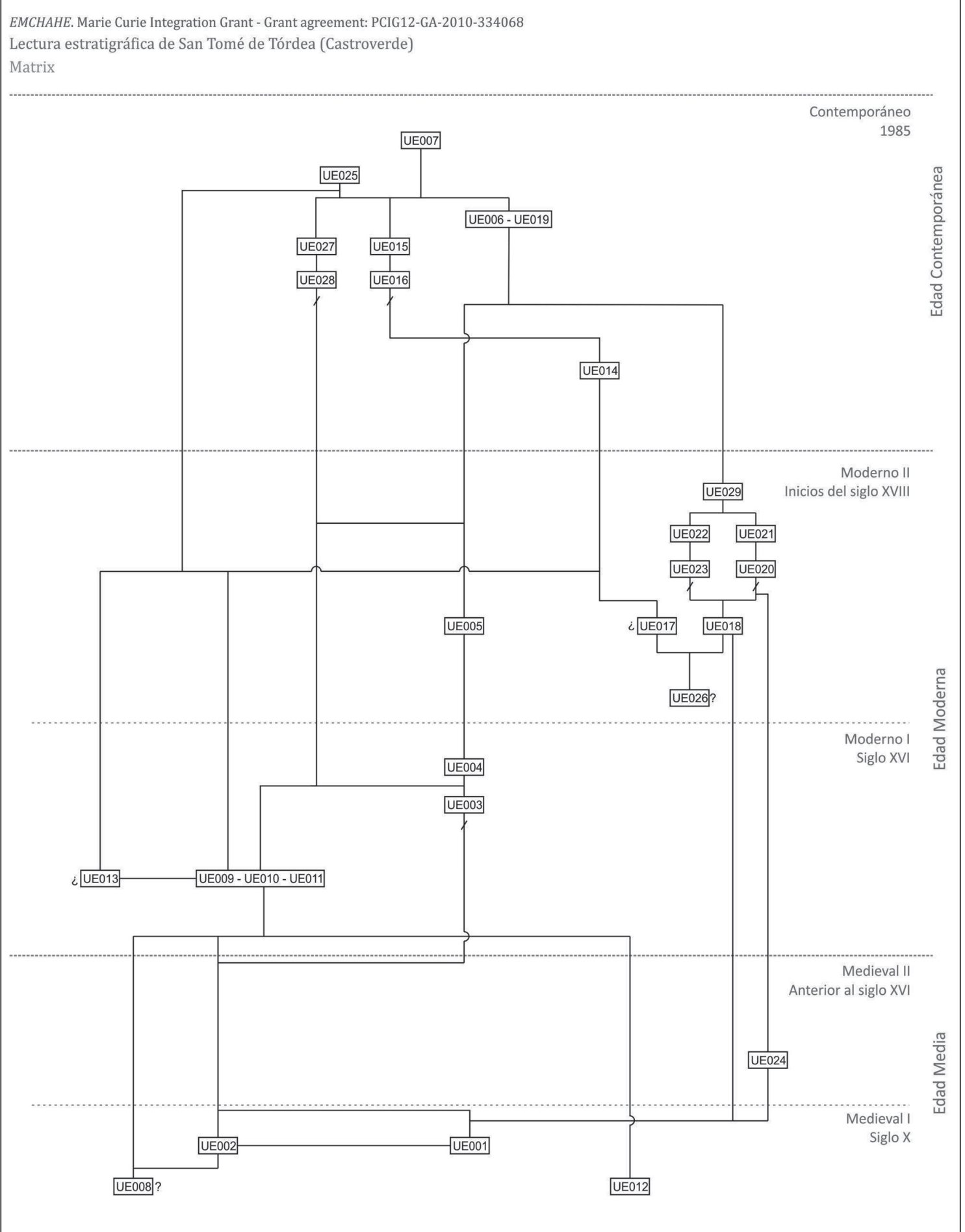

Figura 16. Diagrama estratigráfico de la iglesia de Santo Tomé de Tórdea. 
Tabla 1. Listado de unidades estratigráficas de la iglesia

\begin{tabular}{|c|c|c|c|c|c|c|c|}
\hline Fase & Nombre de la fase & UE & Nombre de la UE & Sector & Anterior a & Coetáneo a & Posterior a \\
\hline \multirow[t]{4}{*}{$\mathrm{T}$} & \multirow[t]{4}{*}{$\begin{array}{l}\text { Edificio original de sillería de } \\
\text { granito reutilizada, sillarejo y } \\
\text { silleria encadenada en los } \\
\text { esquinales. De cabecera } \\
\text { única de planta } \\
\text { cuadrangular, fechado en el } \\
\text { siglo X. }\end{array}$} & 001 & $\begin{array}{l}\text { Muro que conforma la parte baja del alzado este y el } \\
\text { esquinal SE del ábside. Formado por una sillería de } \\
\text { granito de grano grueso dispuesta a soga y tizón en las } \\
\text { esquinas y un sillarejo irregular en el muro, alternado } \\
\text { con una hilada de sillería a la altura de la base de la } \\
\text { ventana saetera. Se documenta un ladrillo macizo que } \\
\text { podría ser reutilizado. La forma de los materiales es } \\
\text { bastante irregular. Las piezas se disponen siguiendo } \\
\text { hiladas, que se rompen y doblan. Las juntas son muy } \\
\text { anchas y actualmente están rehundidas y rellenas de } \\
\text { un mortero de cemento gris (UE025). En el muro, hacia } \\
\text { la parte baja, se localiza una ventana saetera bastante } \\
\text { alta rematada por un arquillo de medio punto. Esta } \\
\text { pieza es de grano más fino que las otras y conserva } \\
\text { huellas de gradina, que creemos habría que relacionar } \\
\text { con un posible revestimiento exterior de la iglesia. El } \\
\text { esquinal SE conserva mayor altura que el NE. }\end{array}$ & Sur / Este & $\begin{array}{|lr|}003, & 004, \\
005, & 009, \\
018, & 023, \\
024, & 025\end{array}$ & 002 & \\
\hline & & 002 & $\begin{array}{l}\text { Muro de sillarejo regular localizado en la mitad inferior } \\
\text { del muro sur del ábside, realizado con piezas } \\
\text { rectangulares y cuadrangulares, generalmente } \\
\text { dispuestas a soga, siguiendo hiladas horizontales, } \\
\text { bastante regulares, que en alguna zona doblan. } \\
\text { Alternancia en la altura de las hiladas. En la parte } \\
\text { superior este está cortado por la UE003 para disponer } \\
\text { una ventana de la UE004. }\end{array}$ & Sur & \begin{tabular}{|l|}
$003, \quad 004$, \\
009,025
\end{tabular} & 001 & 008 \\
\hline & & 008 & $\begin{array}{l}\text { Zócalo documentado en el esquinal SE de la nave, } \\
\text { realizado con piezas de tamaño medio de granito de } \\
\text { grano grueso. Sobresale del paño del muro y tiene una } \\
\text { orientación distinta a la de la nave, al menos el alzado } \\
\text { sur. Conserva } 1 \text { hilada en el alzado sur y } 2 \text { en el este. } \\
\text { La piedra que hace esquina es la que más sobresale } \\
\text { de la planta de la nave y está cortada haciendo un } \\
\text { escalón. Por la forma, podria tratarse de una moldura } \\
\text { reutilizada. }\end{array}$ & Sur, Este & $\begin{array}{|ll|}002, & 009, \\
025 & \\
\end{array}$ & & \\
\hline & & 012 & $\begin{array}{l}3 \text { hiladas de sillarejo situadas en la parte inferior del } \\
\text { muro norte de la nave, en la mitad oeste. Está formado } \\
\text { por piezas de granito de grano grueso dispuestas en } \\
\text { hiladas horizontales, aunque algo inclinadas, por lo que } \\
\text { las hiladas van desapareciendo bajo el nivel del suelo } \\
\text { actual, hacia la parte este del muro. }\end{array}$ & Norte & $\begin{array}{|ll|}011, & 013, \\
025 & \\
\end{array}$ & & \\
\hline II & $\begin{array}{l}\text { Reforma la parte alta del } \\
\text { ábside anterior al siglo XVI }\end{array}$ & 024 & $\begin{array}{l}\text { Muro localizado en la parte alta del alzado este del } \\
\text { ábside, realizado en un aparejo de sillarejo irregular de } \\
\text { granito de grano grueso y fino fundamentalmente, } \\
\text { esquisto muy pizarroso, un canto rodado y un ladrillo } \\
\text { macizo. Algunas piezas de granito muy largas similares } \\
\text { a las de la UE001. La base presenta hiladas inclinadas, } \\
\text { y en la parte alta pseudohiladas horizontales que } \\
\text { doblan y ondulan. Parece incluir el esquinal NE, de } \\
\text { sillería encadenada, pero el mortero de cemento } \\
\text { desvirtúa bastante el aparejo para poder determinar la } \\
\text { existencia o no de una interfaz. Se reutiliza una gran } \\
\text { ventana-celosía cuatrilobulada, calada en la parte } \\
\text { superior. }\end{array}$ & Este & \begin{tabular}{|l|}
018, \\
020,021
\end{tabular} & & 001 \\
\hline \multirow[t]{3}{*}{ III } & \multirow{3}{*}{$\begin{array}{l}\text { Reforma llevada a cabo en } \\
\text { el siglo XVI que incluye la } \\
\text { construcción de la fachada } \\
\text { Oeste, la Norte y parte de la } \\
\text { Sur. }\end{array}$} & 003 & $\begin{array}{l}\text { Corte practicado en las UE001 y } 002 \text { para abrir una } \\
\text { ventana. Se localiza en el lado este del muro UE002. } \\
\text { Tiene forma irregular. }\end{array}$ & Sur & 004,025 & & 001,002 \\
\hline & & 004 & \begin{tabular}{|l|} 
Muro de mamposteria irregular de pequeño/medio \\
tamaño, realizado sobre todo con lajas de esquisto y \\
algún mampuesto de granito, situado en el alzado sur \\
del ábside, sobre el muro UE002. Las piezas se \\
disponen en hiladas aunque ondulantes e inclinadas y, \\
en muchos casos, se cortan. Parece tratarse de una \\
reparación en altura del alzado sur del ábside. Incluye \\
una ventana rectangular adintelada, con doble derrame \\
realizada con cuatro piezas de silleria de granito de \\
grano grueso, cuyos bordes exteriores son irregulares. \\
\end{tabular} & Sur & 005,025 & & $\begin{array}{l}001,002,003 \\
009\end{array}$ \\
\hline & & \begin{tabular}{ll|}
$009 !$ \\
$010 \prime$ \\
011
\end{tabular} & $\begin{array}{l}\text { Muro que conforma los paramentos sur y oeste de la } \\
\text { nave y parte del norte, realizado en un aparejo de } \\
\text { mamposteria, con piezas de tamaño pequeño-medio de } \\
\text { esquisto, granito, cuarcitas y cantos rodados, y } \\
\text { materiales reutilizados (claves de bóvedas decoradas). } \\
\text { Las piezas se disponen horizontalmente formando } \\
\text { pseudohiladas; se aprecia alguna hilada de } \\
\text { regularización. Presenta una mayor regularidad en la } \\
\text { parte baja del muro, sobre todo en la parte norte del } \\
\text { paramento oeste y la parte oeste del paramento sur. } \\
\text { Los esquinales y los vanos están realizados en sillería } \\
\text { de granito, formada por piezas irregulares y materiales } \\
\text { reutilizados (miliarios romanos, estelas posiblemente } \\
\text { altomedievales); en los esquinales los sillares se } \\
\text { disponen encadenados. } \\
\text { La fachada sur contiene un vano-saetera rematado en } \\
\text { un pequeño arquillo; una puerta de jambas rectas } \\
\text { rematadas por ménsulas lisas (una de ellas es una } \\
\text { estela reutilizada) sobre las que descansa un tímpano } \\
\text { sin decorar. La puerta al interior está rematada por un } \\
\text { arco mixtilineo. } \\
\text { La fachada oeste incluye una puerta realizada en } \\
\text { silleria de granito de grano fino de gran tamaño. Está } \\
\text { rematada por un arco de medio punto adovelado. } \\
\text { Sobre la puerta se localiza una ventana saetera } \\
\text { rectangular y sobre esta una espadaña de un solo } \\
\text { cuerpo, rematada por un arco de medio punto y una } \\
\text { cruz sencilla con pináculos a los lados. La fachada está } \\
\text { rematada por una moldura formada por un filete y } \\
\text { cuarto bocel. }\end{array}$ & $\begin{array}{l}\text { Sur, } \\
\text { Norte, } \\
\text { Oeste }\end{array}$ & $\begin{array}{|ll|}¿ 004 ? & 007 \\
015, & 025 \\
028 & \\
\end{array}$ & ¿013? & $002,008,012$ \\
\hline
\end{tabular}


Tabla 1 (continuación)

\begin{tabular}{|c|c|c|c|c|c|c|c|}
\hline Fase & Nombre de la fase & UE & Nombre de la UE & Sector & Anterior a & Coetáneo a & Posterior a \\
\hline & & & $\begin{array}{l}\text { En la fachada norte se conserva únicamente el } \\
\text { esquinal. }\end{array}$ & & & & \\
\hline & & 013 & $\begin{array}{l}\text { Muro de sillarejo de granito de grano grueso situado en } \\
\text { la parte inferior del muro norte de la nave. Algún } \\
\text { material reutilizado. Se dispone en pseudohiladas que } \\
\text { tienden a la horizontalidad, aunque inclinan y alguna } \\
\text { dobla. }\end{array}$ & Norte & 014,025 & ¿011? & ¿011?, 012 \\
\hline \multirow[t]{9}{*}{ IV } & \multirow{9}{*}{$\begin{array}{l}\text { Reformas de inicio del siglo } \\
\text { XVIII, que incluyen una } \\
\text { sacristia que se adosa al } \\
\text { paramento Norte del ábside. }\end{array}$} & 005 & $\begin{array}{l}\text { Reforma de mampostería irregular de granito de } \\
\text { pequeño tamaño y algún sillar/bloque de granito } \\
\text { reutilizado, situada sobre el muro UE004. }\end{array}$ & Sur & 006-019, 025 & 020,021 & $001,004,009$ \\
\hline & & 017 & $\begin{array}{l}\text { Posible reparación del alzado oeste de la sacristía } \\
\text { (UE018). Realizada en mampostería de granito, tanto } \\
\text { de grano muy fino como muy grueso, algún esquisto o } \\
\text { pizarra y algún canto rodado. Sobresale del paño del } \\
\text { muro marcado por el esquinal NO de la UE018. Se } \\
\text { apoya sobre un zócalo (UE026). }\end{array}$ & Norte & 025 & ¿018? & ¿018?, 026 \\
\hline & & 018 & $\begin{array}{l}\text { Muro de mampostería de gran tamaño, con esquinales } \\
\text { de sillería dispuesta a soga y tizón que forma los } \\
\text { alzados norte, este y el esquinal oeste de la sacristia } \\
\text { adosada a la fachada norte del ábside. Abundante } \\
\text { material reutilizado. En la parte baja se dispone una } \\
\text { hilada de grandes bloques sin trabajar. En algunas } \\
\text { zonas el aparejo forma pseudohiladas. El alzado norte } \\
\text { incluia una ventana hoy cegada con mortero de } \\
\text { cemento (UE025). }\end{array}$ & $\begin{array}{l}\text { Norte, } \\
\text { Este }\end{array}$ & $\begin{array}{ll}¿ 017 ?, & 019, \\
020, & 021, \\
022, & 023, \\
025 & \end{array}$ & ¿017? & 001 \\
\hline & & 020 & $\begin{array}{l}\text { Tres mechinales rectangulares abiertos en las UE018 y } \\
\text { UE024, para disponer unas vigas de madera de una } \\
\text { cubierta anterior a la actual. }\end{array}$ & Este & 021,025 & & 018,024 \\
\hline & & 021 & $\begin{array}{l}\text { Tres vigas de madera para sujetar una cubierta anterior } \\
\text { que se situaba a una altura inferior en la fachada este } \\
\text { de la iglesia. Las vigas han sido amortizadas en la UEs } \\
\text { UE006-019. }\end{array}$ & Este & 025 & & 020 \\
\hline & & 022 & $\begin{array}{l}\text { Mechinal rectangular abierto en las UE017 y UE018, } \\
\text { para disponer una viga de madera que sujetaba una } \\
\text { cubierta más baja que la actual. Se localiza en el muro } \\
\text { oeste de la sacristía. }\end{array}$ & Oeste & 025,029 & & \\
\hline & & 023 & $\begin{array}{l}\text { Cabeza de viga de madera para sujetar una cubierta } \\
\text { anterior más baja, en la fachada oeste de la sacristía. } \\
\text { Las vigas han sido amortizadas en las UEs } 006-019 \text {. }\end{array}$ & Oeste & $\begin{array}{ll}022, & 025, \\
029 & \end{array}$ & & 017,018 \\
\hline & & 026 & $\begin{array}{l}\text { Zócalo que sobresale del alzado oeste de la sacristía. } \\
\text { Son unas cinco piezas de granito que sobresalen } \\
\text { irregularmente del muro UE018. }\end{array}$ & $\begin{array}{l}\text { Oeste, } \\
\text { Norte }\end{array}$ & $\begin{array}{l}i 013 ?, 017 \\
018,025\end{array}$ & & $018,022,023$ \\
\hline & & 029 & $\begin{array}{l}\text { Restos de lajas de pizarra de la anterior cubierta, se } \\
\text { aprecian en el muro norte de la sacristia. }\end{array}$ & Norte & 019,025 & & \\
\hline \multirow[t]{8}{*}{$\mathrm{V}$} & \multirow[t]{8}{*}{$\begin{array}{l}\text { Reformas contemporáneas, } \\
\text { llevadas a cabo } \\
\text { fundamentalmente en 1985, } \\
\text { tras la caída de la fachada } \\
\text { Norte de la nave. Incluye el } \\
\text { cambio de cubierta. }\end{array}$} & $\begin{array}{l}006- \\
019\end{array}$ & $\begin{array}{l}\text { En la revisión de la secuencia, se equiparan ambas } \\
\text { UEs. Elevación en la parte superior de los alzados sur y } \\
\text { este del ábside, y este, norte y oeste de la sacristía } \\
\text { para elevar la cubierta y disponerla a la misma altura } \\
\text { que la de la nave en el alzado sur de toda la iglesia. Es } \\
\text { un murete realizado con una mampostería irregular de } \\
\text { tamaño pequeño-medio, con piezas de granito, } \\
\text { esquisto y canto rodado de cuarcita. Las juntas son } \\
\text { anchas y están rellenas con mortero de cemento. }\end{array}$ & $\begin{array}{l}\text { Norte, } \\
\text { Sur, Este, } \\
\text { Oeste }\end{array}$ & 007,025 & & $\begin{array}{l}005,017,018, \\
020,021,022, \\
023,024,027\end{array}$ \\
\hline & & 007 & $\begin{array}{l}\text { Cubierta de pizarra a dos aguas, con las piezas de la } \\
\text { cumbrera entrelazadas en crestería. Se dispone sobre } \\
\text { la UE006-019. }\end{array}$ & $\begin{array}{l}\text { Sur, Este, } \\
\text { Norte, } \\
\text { Oeste }\end{array}$ & $\begin{array}{l}006-019 \\
010,011 \\
015,016 \\
027,028\end{array}$ & & \\
\hline & & 014 & $\begin{array}{l}\text { Muro que forma la mayor parte de la fachada norte de } \\
\text { la nave. Se emplea una técnica mixta que combina la } \\
\text { mamposteria y el sillarejo. Incluye numerosas piezas } \\
\text { reutilizadas, entre ellas un fragmento de epigrafe. } \\
\text { Incluye dos ventanas rectangulares adinteladas. }\end{array}$ & Norte & $\begin{array}{l}007,015, \\
016,025\end{array}$ & ¿017? & $\begin{array}{l}011,013 \\
\text { ¿017? }\end{array}$ \\
\hline & & 015 & $\begin{array}{l}\text { El muro tiene las juntas muy anchas. Se emplea granito } \\
\text { de grano grueso y fino, esquistos, pizarras y cantos } \\
\text { rodados. }\end{array}$ & Norte & 007,025 & ¿016? & 011,014 \\
\hline & & 016 & $\begin{array}{l}\text { Remate del muro norte de la nave realizado en } \\
\text { mampostería de pequeño tamaño. Para regularizar la } \\
\text { parte superior del muro y disponer la cubierta. }\end{array}$ & Norte & 015,025 & & \\
\hline & & 025 & $\begin{array}{l}\text { Rejuntado de todas las fachadas exteriores de la iglesia } \\
\text { con mortero de cemento. }\end{array}$ & $\begin{array}{l}\text { Norte, } \\
\text { Sur, Este, } \\
\text { Oeste }\end{array}$ & $\begin{array}{l}\text { Todas las } \\
\text { UEs excepto } \\
\text { la UE007 }\end{array}$ & & \\
\hline & & 027 & $\begin{array}{l}\text { Mechinales abiertos en el coronamiento del muro sur } \\
\text { de la nave. Relacionados con la construcción de la } \\
\text { actual cubierta (UE028 - UE007). Tienen forma } \\
\text { cuadrangular y están rellenos por la UE028. } \\
\text { Posiblemente se trate de mechinales para disponer las } \\
\text { vigas de madera de la cubierta. }\end{array}$ & Sur & 007,025 & & $009-010,028$ \\
\hline & & 028 & $\begin{array}{l}\text { Remate del muro sur de la nave realizado en } \\
\text { mampostería de pequeño tamaño. Para regularizar la } \\
\text { parte superior del muro y disponer la cubierta. }\end{array}$ & Sur & $006-019$ & & $\begin{array}{l}017,018,022, \\
023\end{array}$ \\
\hline
\end{tabular}

\section{Discusión}

El análisis estratigráfico realizado muestra la existencia de cinco fases constructivas en la iglesia de Santo Tomé de Tórdea. Evidencias estilísticas, documentales y epigráficas permiten datar sin demasiados problemas las tres últimas fases en el siglo XVI, en 1719 y 1985 respectivamente. La cuestión, por tanto, que queda por resolver es la datación de la primera y segunda fase. 
Como ya hemos señalado, algunas de las características constructivas de la primera fase, como el uso de técnicas mixtas que combinan sillería con piezas reutilizadas, sillarejo y sillería encadenada en los esquinales, o el desdoble de hiladas parecen encajar bien con técnicas constructivas altomedievales, que hemos identificado y fechado de forma absoluta en otros ejemplos gallegos, como en San Martiño de Pazó, datada en el siglo X (SÁNCHEZ-PARDO et al. 2017). No obstante, Jaime Delgado consideraba que la ventana saetera del ábside que incluimos en esta primera fase es estilísticamente románica y por ello aboga por la existencia de una fase de este período en este templo. Sin embargo, él mismo admitía que dicha ventana no podría estar en su lugar original pues se situaba demasiado abajo con respecto a la posición habitual de este tipo de óculos en construcciones románicas. Por nuestra parte, además de confirmar con la lectura estratigráfica que dicha ventana se encuentra in situ, consideramos que existen paralelos en edificios prerrománicos tanto de este tipo de ventanas saeteras como de su ubicación en la zona inferior del ábside, como sucede en Santa María de Mixós, datada en el siglo IX (SÁNCHEZ-PARDO et al. 2018). Otro de los argumentos que manejaba Delgado para adscribir esta ventana saetera a época románica es la incompatibilidad con la presencia de otra ventana prerrománica (la celosía cuadrilobulada) situada por encima de ella. Sin embargo, el análisis estratigráfico revela que la celosía cuadrilobulada fue colocada ahí en una fase posterior, sin que sepamos cuál era su procedencia original, que no tendría que ser el ábside. De hecho, existen abundantes paralelos de iglesias prerrománicas en las que las ventanas celosías están situadas en otras partes del edificio como la fachada principal (Santa Cristina de Lena) o formar parte del cancel (en la misma Santa Cristina de Lena se documentan sobre el espacio del cancel, o en San Julián de los Prados en varios paramentos del edificio). En la propia iglesia de San Estevo de Atán, con la que se suele comparar la celosía de Tórdea, se conservan dos tipos de ventanas prerrománicas: la susodicha celosía similar a la que nos ocupa, y una ventana geminada que por paralelos es más probable que hubiese estado situada en el ábside de un hipotético primer edificio altomedieval del que, en todo caso, no quedarían fases en alzado (CABALLERO et al. 2003). Por tanto, los criterios estratigráficos y los paralelos de las técnicas constructivas nos llevan a datar esta primera fase de Santo Tomé de Tórdea en torno a los siglos IXX. Por su parte, el análisis de las piezas estilísticamente prerrománicas reutilizadas en el edificio y sus inmediaciones, podría ajustar más la datación hacia el primer tercio del siglo X. En efecto, la ménsula reaprovechada como pila de agua bendita, con sus características acanaladuras encuentra paralelos en San Miguel de Bóveda, "Santa Ouxea ad Portum” y Santa María de Mixós, mientras que el modillón de dos rollos reutilizado en la fachada de una casa cercana remite parcialmente al conservado en Ferreira de Pallares. Esta serie de piezas tienden a datarse entre finales del siglo IX y primera mitad del siglo X (YZQUIERDO 1993: 144-151), aunque hay que recordar que las piezas de Tórdea están descontextualizadas por lo que no tenemos plena certeza de que pertenezcan a la iglesia original. Por su parte, la ventana saetera remite al caso de Santa María de Mixós (aunque en Tórdea su longitud es sensiblemente mayor y su técnica constructiva distinta) y el propio Jaime Delgado data la celosía cuadrilobulada en el siglo X. Cabe señalar también que la reutilización de miliarios romanos en iglesias es una práctica bien constatada en 
la alta edad media gallega (SASTRE DE DIEGO 2009) aunque no podamos saber en qué momento se incorporaron a la iglesia de Tórdea.

Otra de las consecuencias de asignar esta primera fase al período prerrománico es que podríamos tener indicios de cuál era la planta de esa primera iglesia del siglo $\mathrm{X}$. Dado que conservamos buena parte de la planta del ábside, así como del zócalo oriental de la nave sur y posiblemente, parte del aparejo inferior de la nave norte en su extremo occidental, resulta posible establecer las dimensiones del ábside original y de la anchura de la nave, no así su largura pues la fachada pertenece a un momento posterior. Parece, por tanto, probable que se tratase de un templo de cabecera única cuadrangular con el mismo ancho actual ( 9 metros). La anchura de las naves permitiría proponer una división interna en 3 naves, algo habitual en las iglesias prerrománicas de los siglos IX-X, si bien se trata tan sólo de una hipótesis.

Por último, la existencia de una placa funeraria del año 794 junto a la estela discoidea parece apuntar algunos indicios sobre la posible existencia de una necrópolis en el entorno de la iglesia, que existiría ya a finales del siglo VIII, con lo cual no es descartable (aunque tampoco necesario) que hubiese ya un templo asociado a la misma en esos momentos, del que en todo caso no tenemos ninguna evidencia.

Por otra parte, la lectura estratigráfica apunta a la existencia de una segunda fase en la que tendría lugar la reforma de la parte superior del ábside. Sin embargo, a diferencia de la primera fase, no poseemos indicadores cronológicos que nos proporcionen una datación clara para la misma. Sólo podemos decir que a nivel de cronología relativa esta segunda fase se sitúa entre el siglo X y el siglo XVI (asumiendo que es en ese momento -la tercera fase constructiva- cuando se realizan las pinturas que cegaban parcialmente el interior del óculo cuadrilobulado). En todo caso, proponemos que esta segunda fase estaría más cercana en el tiempo a la tercera que a la primera. De hecho, a diferencia de lo que plantea Delgado, creemos que no hay razones para hablar de una fase románica (siglos XII-XIII) en esta iglesia. Ninguna de las piezas empleadas en las distintas fases del edificio o halladas en sus proximidades remite estilísticamente a ese período, y sí en cambio a los períodos altomedievales (celosía, ménsula, modillón, estela discoidea, ventana saetera y posible friso decorado), renacentista (claves de bóveda y pinturas) y siglo XVIII (ventanas de la sacristía). Frente a esta abundancia de elementos de esos periodos, llama la atención que no tengamos constancia de ninguna pieza claramente románica. Delgado propone que la espadaña pertenecería a este momento, pero como hemos visto, debe encuadrarse constructiva (y estilísticamente) en la fase adscrita al siglo XVI. Este autor también considera que la ventanita aspillera del lado sur y la pila bautismal pertenecen a este período, pero en nuestra opinión su estilo puede encajar en momentos más tardíos.

Ya en el siglo XVI tendría lugar una importante reforma de la iglesia en estilo renacentista (sin descartar, como hemos dicho, que la segunda fase también sea de este momento o ligeramente anterior). Se trataría de una construcción de cierta entidad, como muestra el hecho de que tuviera bóvedas posiblemente de crucería (de las que se conservan las claves planas decoradas reutilizadas en la siguiente fase) y estuviese ricamente adornada con pinturas, como aún se observa en el ábside. Por algún tipo de razón las bó- 
vedas fueron desmontadas a inicios del siglo XVIII, o bien la iglesia sufrió un colapso en torno a este momento, cuando se procede a construir la sacristía anexa. Y como ya hemos dicho, nuevas reformas tuvieron lugar ya en época contemporánea, especialmente en 1985 con la reconstrucción de buena parte del muro norte y algunos tramos del sur. Toda esta serie de abundantes reformas hacen pensar que esta construcción debió sufrir algún tipo de inestabilidad o problemas estructurales a lo largo de su historia que obligaron a su constante reconstrucción.

\section{Conclusiones}

Santo Tomé de Tórdea constituye un edificio de gran interés histórico y arqueológico, que ha pasado sorprendentemente desapercibido hasta la fecha. La prospección y estudio estratigráfico que hemos realizado ha demostrado que esta iglesia conserva en pie una fase altomedieval que puede datarse probablemente hacia inicios del siglo X. Se trataría de los restos de un antiguo edificio de ábside cuadrangular con una nave de 9 metros de ancho (quizá de 3 naves en su interior), realizado en una buena técnica constructiva, con sillarejo y sillería, y una serie de elementos de decoración arquitectónica como ménsulas, celosías y modillones que -asumiendo razonablemente que procedan de este mismo edificio- indicarían que se trataba de una construcción de gran calidad arquitectónica. En este sentido, es posible que se trate de la iglesia de "Sancto Iuliano de Tordena" que a finales del siglo X pertenecía al patrimonio particular del obispo Pelayo de Lugo; es decir, estaba en manos de un rico aristócrata del momento, aunque no sepamos cómo ni cuándo habría llegado a él. A esta calidad constructiva del primer edificio conservado se une el interés de su emplazamiento a los pies de la antigua vía XIX romana y los indicios de la existencia de una necrópolis en su entorno inmediato desde al menos desde finales del siglo VIII. Posteriores reformas transformarían notablemente el edificio original, aunque podemos pensar que no variaron en exceso su planta y dimensiones. En este sentido conviene recordar que la iglesia de Santo Tomé de Tórdea constituye una de las pocas edificaciones que conserva alzados prerrománicos en la zona norte de Galicia, y sin duda se hace merecedora de nuevos y más profundos estudios que continúen aclarando su interesante evolución histórica y arqueológica.

\section{Bibliografía}

ARIAS VILAS, F., (1998) “A propósito das estelas discoideas de Castillós (Pantón)”, Croa, 8, 40-41. BROGIOLO, G. P. (1988). Archeologia dell'edilizia storica, Como.

CABALLERO ZOREDA, L. (1995). "Método para el análisis estratigráfico de construcciones históricas o "lectura de paramentos"”, Informes de la Construcción, 453, pp. 37-46. DOI: https://doi. org/10.3989/ic.1995.v46.i435.1096

CABALLERO ZOREDA, L. (1996). "El análisis estratigráfico de construcciones históricas". En L. Caballero Zoreda; C. Escribano Velasco (Eds). Arqueología de la Arquitectura. El método arqueológico aplicado al proceso de estudio y de intervención en edificios históricos. Salamanca, pp. 55-74. 
CABALlERO, L.; ARCE, F.; UTRERO, M. A., (2003). "San Esteban de Atán (Lugo). Un ejemplo de iglesia que no es lo que parece". Arqueología de la Arquitectura, 2, 63-68. DOI: https://doi. org/10.3989/arq.arqt.2003.25

CABARCOS FERNÁNDEZ, I., (2006-2008). "Ménsulas e canzorros medievais no museo provincial de Lugo”, Boletín do Museo Provincial de Lugo, 13, 235-252.

CAÑIZARES DEL REY, V. (2012), Colección Diplomática (569-1463), ed. de Manuel Rodríguez Sánchez y Oscar González Murado, Lugo.

DELGADO GÓMEZ, J., (1996-2006). El románico de Lugo y su provincia, A Coruña.

EGUILETA FRANCO, J. M.; SERRULLA RECH, F.; XUSTO RODRÍGUEZ, M., (1992). "Resultados de los sondeos arqueológicos en las necrópolis medievales de Manín (San Salvador de Manín, Lobios, Ourense)", Boletín Auriense, XXII, 33-71.

MAÑANA-BORRAZÁS, P.; BLANCO-ROTEA, R.; SÁNCHEZ-PARDO, J. C., (2016), "Fast 3D recording techniques: a low-cost method for the documentation and analyisis of scattered architectural elements as part of the EMCHAHE project”, En H. Kamermans, W. de Neef, C. Piccoli, A. G. Posluschny, R. Scopigno (eds). The three dimensions of Archaeology, Oxford, pp. 99-110.

RODRÍGUEZ COLMENERO, A., (2005). "Arte y civilización en la Gallaecia romana”, En VVAA (eds), Arte e Cultura de Galicia e Norte de Portugal. Arqueoloxía I, Vigo, pp. 9-47.

RODRÍGUEZ COLMENERO, A.; FERRER SIERRA, S.; ÁlVAREZ ASOREY, R., (2004). Miliarios $e$ outras inscricións viarias romanas do Noroeste Hispánico (Conventos Bracarense, Lucense e Asturicense), Santiago de Compostela.

SÁNCHEZ ZUFIAURRE, L., (2007). Técnicas constructivas medievales. Nuevos documentos arqueológicos para el estudio de la Alta Edad Media en Álava, Vitoria.

SÁNCHEZ-PARDO, J. C.; BLANCO-ROTEA, R.; SANJURJO-SÁNCHEZ, J.; GONZÁLEZ-GARCÍA, A. C. (2018). "Cronotipología y datación absoluta de iglesias altomedievales en Galicia. Primeros resultados del proyecto EMCHAHE”, Hortus Artium Medievalium 24, 90-104. DOI: HTTPS://DOI. ORG/10.1484/J.HAM.5.115940

SÁNCHEZ-PARDO, J.C., BLANCO-ROTEA, R. (2014). "Early Medieval Churches. History, Archeology and Heritage (2013-2017). Marie Curie EMCHAHE project", The European Archaeologist (TEA), 42, pp. 83-85.

SÁNCHEZ-PARDO, J.C., BLANCO-ROTEA, R., SANJURJO-SÁNCHEZ, J. (2017). "Tres arquitecturas altomedievales ourensanas: Santa Eufemia de Ambía, San Xés de Francelos y San Martiño de Pazó". Arqueología de la Arquitectura, 17: eo62, DOI: https://doi.org/10.3989/arq.arqt.2017.017 SASTRE DE DIEGO, I., (2009). El altar en la arquitectura cristiana hispánica. Siglos V-X. Estudio arqueológico. Tesis doctoral inédita, Madrid.

VALIÑAS SAMPEDRO, E. (1983), Inventario artístico de Lugo y su provincia. Tomo VI, Madrid. 